\title{
Deformation behaviour of lean duplex stainless steels with strain induced martensitic transformation: role of deformation mechanisms, alloy chemistry and pre-deformation
}

\author{
Audrey Lechartier ${ }^{1,2}$, Nicolas Meyer ${ }^{2}$, Rafael Estevez ${ }^{1}$, Marc Mantel ${ }^{1,2}$, Guilhem Martin ${ }^{1}$, \\ Guillaume Parry ${ }^{1}$, Muriel Veron ${ }^{1}$, Alexis Deschamps ${ }^{1}$
}

${ }^{1}$ Univ. Grenoble Alpes, CNRS, Grenoble INP, SIMaP, F-38000 Grenoble, France

${ }^{2}$ UGITECH, F-73403 Ugine Cedex, France

\section{Keywords}

TRIP-aided duplex stainless steels ; strain-induced martensite ; strain hardening ; high energy X-ray diffraction

Declaration of interest : None

\begin{abstract}
The design of duplex stainless steels (DSS) with strain induced martensite (SIM) transformation relies on the optimization of austenite stability. The goal is to achieve a distribution of SIM over a wide range of strain so as to get the best combination of strength and ductility. A systematic study of plastic deformation mechanisms, of the link between phase chemistry, SIM kinetics and related stress-strain behavior has been carried out by combining advanced characterization: orientation mapping in the transmission electron microscope, in-situ high energy X-ray diffraction, and microscopic digital image correlation. The role of $\mathrm{Ni} / \mathrm{N}$ balance on controlling the austenite stability has been investigated in medium-Ni lean DSS steels containing $4 \mathrm{wt} \%$ Ni. Results show that SIM occurs in the DSS by a two-steps transformation: first some austenite transforms into $\varepsilon$-martensite and the latter subsequently transforms into $\alpha^{\prime}$-martensite at the intersections of $\varepsilon$-bands and further grow into the austenite. It is found that SIM formation occurs at a slower kinetics in the DSS as compared to its fully austenitic counterpart, however with a similar relationship to flow stress. An optimal level of mechanical behavior is shown to be related to an optimal rate of SIM formation during tensile testing. The yield strength can be improved by rolling with a limited impact on the phase transformation potential.
\end{abstract}

\section{Introduction}

Lean Duplex stainless steels (DSS), consisting of austenite and ferrite in approximately equal proportions, offer attractive combinations of strength, elongation and corrosion resistance at a reasonable cost in comparison with conventional DSS grades due to lower content of elements such as Ni or Mo [1,2]. Several classes of lean DSS grades have been developed, depending on the main element used to stabilize the austenite, Ni or Mn, and also on the content of Mo used to improve the corrosion resistance. The most recent developed lean duplex grades use $\mathrm{Mn}$ as the main austenite stabilizer to minimize the addition of $\mathrm{Ni}$ [3-6]. This provides an increased strength / elongation potential, however at the expense of a lower resistance to corrosion and fracture as well as to longterm ageing [7,8]. With intermediate levels of $\mathrm{Ni}$, lean duplex grade 1.4362 (UNS S32304), employed in construction applications [9,10] contains a $\mathrm{Cr}$ content of the order of $22 \%$, a Ni content 
of approximately $4 \%$ in addition to other alloying elements $(\mathrm{N}, \mathrm{Mn}, \mathrm{C}, \ldots)$ [11]. It is now well established that the key to optimize the strength / elongation compromise is the control of the stability of austenite during plastic deformation. The austenite is chemically adjusted to be metastable during plastic deformation and thus transform via a Transformation Induced Plasticity (TRIP) effect [12,13]. The formation of strain-induced martensite (SIM) during plastic deformation increases the strain hardening rate which prevents plastic localization, thus increasing both the ultimate tensile strength (UTS) and total elongation [14]. The underlying mechanism of the formation of SIM may take several forms depending on the alloy composition and thus on the stacking fault energy. In the class of alloys of interest here, it is widely accepted that the transformation starts first with the transformation of austenite into hexagonal $\varepsilon$-martensite, followed by the transformation into $\alpha$ ' martensite at the intersection of two $\varepsilon$ bands, and further growth of $\alpha$ ' in the $\gamma$ matrix [15-18].

In order to reach the best compromise between strength and ductility, the stability of austenite must be carefully tuned [13]. In the case of an excessive austenite instability, the SIM transformation starts at small plastic strains and rapidly saturates, which results in a high strength but a rather low elongation. On the contrary, in the case of excessive austenite stability, triggering the TRIP effect may occur too late to prevent premature necking and failure. As a result, ideally, the TRIP effect should be tuned to allow the strain hardening rate to remain just above the true stress until large strains are achieved.

Several ways have been explored to optimize the austenite stability. For a given alloy composition, the temperature of the heat treatment leading to the duplex microstructure influences both the proportion of ferrite and austenite, and the partitioning of the alloying elements between these two phases and thus the stability of austenite [6,19-23]. However, these two parameters cannot be changed independently and therefore the austenite stability is fixed (at first order) by the requirement of an equal proportion of the two constituent phases in the microstructure of a DSS. Adjusting the alloy composition is the most obvious way to optimise the austenite stability at constant phase fractions [24]. However, other parameters need also to be evaluated, particularly, the austenite transformation "kinetics", namely its evolution with strain. The transformation kinetics is strongly influenced by the size and morphology of the austenite grains [25], as well as the strain rate [26], in the latter case due to adiabatic heating preventing the TRIP effect when the strain rate is increased. In addition, for applications such as reinforcement bars for concrete, DSS are subjected to pre-deformation, which may play a role by improving the yield stress and modifying the elongation to failure [27].

In order to carry out a systematic and comprehensive approach to DSS optimization one thus needs to carry out a multi-scale approach, combining several complementary objectives:

(i) Studying the microscopic deformation mechanisms, particularly those leading to SIM formation;

(ii) Evaluating the specific role of the two-phase structure of a DSS (as compared to singlephase austenite) on the strain-induced phase transformation and related stress-strain behaviour; stability;

(iii) From this knowledge, optimizing the properties of DSS by controlling the austenite

(iv) A full understanding of the prevailing mechanisms requires not only the measurement of macroscopic properties but also a quantification of the phase fractions in the dynamically transforming microstructures.

To the author's knowledge, such an integrated approach is not yet available in the DSS literature. The aim of the present paper is to present such an approach on a series of alloys similar to the 1.4362 grade chemistry, with intermediate Ni content close to $4 \mathrm{wt} \%$, where the austenite stability will be mainly controlled by the level of nitrogen.

For this purpose, a first part will be dedicated to the study of microscopic deformation mechanisms in a DSS by automated crystal and phase orientation mapping in a transmission electron microscope (ACOM-TEM). In a second part, the role of the two-phase microstructure of this DSS will be evaluated by comparing experimentally and numerically its stress-strain response with that of 
model austenitic and ferritic steels representative of the compositions of its two phases. In a third part, four different alloy compositions, specifically designed to provide a wide range of austenite stability will be analysed. The tensile stress-strain behaviour of those four alloys will be presented, in the heat-treated conditions and after different levels of pre-deformation applied by cold rolling. Neutron, or high energy X-ray diffraction are particularly well suited to follow quantitatively the strain-induced phase transformations [14,28-32]. In this study, the fraction of strain-induced martensite formed during straining has been systematically followed using in-situ High Energy Xray Diffraction (HEXRD) performed at the European Synchrotron Radiation Facility (ESRF).

\section{Materials and methods}

The first part of this study was carried out on a duplex stainless steel (hereafter called Duplex alloy) with the following chemical composition Fe-22.12Cr-4.24Ni-1.15Mn-0.28Mo-0.12N-0.021C (wt\%). This duplex grade matches the European standard of the 1.4362 grade. In the second part, single phase alloys (hereafter called austenitic and ferritic alloys) whose composition correspond to the austenitic and ferritic phases of the Duplex alloy were elaborated. They will be presented in details in the Results section.

In the third part, four alloy compositions (hereafter named alloys A, B, C and D) were designed using Thermo-Calc ${ }^{\circledR}$ software with the TCFE6 database in order to (i) maintain an equal proportion of austenite and ferrite under calculated equilibrium at $1000^{\circ} \mathrm{C}$ and (ii) exhibit various degree of austenite stability with respect to room temperature plastic deformation. As a design guide, the austenite stability was estimated based on the Md30 temperature estimated by the empirical Nohara formula [33] applied to the calculated austenite compositions at $1000^{\circ} \mathrm{C}$. This parameter stands for the temperature at which $50 \%$ of the austenite has transformed into martensite after a true strain of 0.3 [34]. Thus, a high Md30 temperature corresponds to unstable austenite and a low Md30 temperature to stable austenite. Chemical compositions were determined by X-ray fluorescence spectrometry, except for carbon and nitrogen that were measured by combustion and gas fusion analysis with a LECO apparatus. Table 1 shows the predicted ferrite fractions and measured chemical composition of the four investigated alloys, with an increasing predicted degree of instability of the austenitic phase from alloy A to D as shown by the Md30 values in Table 2, which also gives the chemical compositions of ferrite and austenite in the four steels. One can notice that alloy $\mathrm{C}$ has a chemical composition close to that of the Duplex alloy. The four alloys A to D were cast using a Vacuum Induction Melting process to ingots of $25 \mathrm{~kg}$. These ingots were hot forged, and subsequently hot rolled at $1180^{\circ} \mathrm{C}$ down to $6 \mathrm{~mm}$ thickness. A solution annealing treatment of $2 \mathrm{~h}$ at $1000^{\circ} \mathrm{C}$ was applied immediately followed by water quenching to avoid detrimental precipitation of the brittle $\sigma$-phase during cooling. Finally, a cold rolling operation of $10 \%$ and $20 \%$ relative thickness reduction was performed when studying the effect of pre-deformation.

For microstructural observations, the samples were prepared by standard surface preparation methods with a final superfinishing using $0.04 \mu \mathrm{m}$ colloidal silica. Microstructures were revealed by electro-etching using an aqueous solution containing $85 \%$ of nitric acid applying a current density of $50 \mathrm{~mA} / \mathrm{cm}^{2}$ for $30 \mathrm{~s}$. The chemical composition of the austenite and ferrite phases have been determined using an electron probe micro-analyser (JEOL JXA-8100). The final respective composition of ferrite and austenite were taken as an average of 10 punctual WDS measurements and the quantification was done using bulk standards. The phases chemical compositions are given in Table 2. For TEM observations, samples were mechanically polished down to $80 \mu \mathrm{m}$, followed by double-jet polishing in an electrolyte consisting of $50 \mathrm{ml}$ perchloric acid, $100 \mathrm{ml}$ methanol and $950 \mathrm{ml}$ of butylglycol at $15^{\circ} \mathrm{C}$ and under a voltage of $25 \mathrm{~V}$. Observations were carried out with a JEOL 2100F instrument at $200 \mathrm{kV}$ in STEM mode. The diffraction diagrams were recorded and analysed to identify the phase and determine the crystallographic orientation using the ASTAR package, see $[35,36]$ for more details regarding the technique.

The respective proportions of ferrite and austenite during tensile tests were quantified by in-situ High Energy X-ray Diffraction (HEXRD) measurements. These measurements were carried out at the ID15B beamline of the ESRF with an X-ray energy of $90 \mathrm{keV}$. The Debye-Scherrer rings were 
collected in transmission mode using a $2 \mathrm{D}$ detector with a frame rate of 4 images per second. The two sample heads were moved symmetrically with respect to the X-ray beam so that it could remain at the centre of the specimen gauge length during the complete tensile test. The sample thickness was $1.6 \mathrm{~mm}$, the width $1.5 \mathrm{~mm}$, the gauge length $17 \mathrm{~mm}$ and the strain rate was $5.10^{-4} \mathrm{~s}^{-1}$. The Debye-Scherrer rings were integrated radially to obtain diffractograms, with a maximum value of $2 \theta$ at $14^{\circ}$, giving access to 24 diffraction peaks for the sum of austenite and ferrite. The phase proportion was then calculated using a Rietveld refinement with the Fullprof software [37,38]. An example of diffractograms evolution is given in supplementary material (Figure S1) during straining of alloy D. The diffraction peaks of the austenite phase almost completely disappear during the tensile tests, while the diffraction peaks of (ferrite + martensite) become stronger, due to the strain-induced phase transformation. In these low-carbon steels it is not possible to discriminate ferrite and martensite. As a result, the evolution of the martensite fraction was calculated from the evolution of austenite, assuming that in the as-heat treated conditions, the microstructure did not contain any martensite (which was confirmed by TEM observations). Although $\varepsilon$-martensite was observed by electron microscopy, it could not be quantified on the HEXRD data, presumably due to a too small volume fraction.

Microscale Digital Image correlation (DIC) was performed on two samples exhibiting a significant difference in terms of austenite stability during an in-situ tensile test in a Scanning Electron Microscope (SEM). In order to create a speckle pattern to enable microscale DIC (at the scale of individual phases) gold nanoparticles were obtained by solid state dewetting according to a protocol detailed in [28]. The DIC analysis was performed using the CorrelManu software, see [39-41] for more details regarding the DIC routines.

\section{Deformation mechanisms}

The study of the microscopic deformation mechanisms was carried out on the Duplex alloy. Figure 1a shows an EBSD phase map of this alloy's initial microstructure (before straining), consisting of a balanced distribution of austenite and ferrite with an average grain size of $20 \mu \mathrm{m}$. Figure $1 \mathrm{~b}$ shows the associated true stress-true strain curve, calculated strain hardening rate, and the evolution of the fraction of martensite as a function of strain (calculated from in-situ HEXRD). These results shed light on the relationship between SIM fraction and the evolution of the stress-strain response. Based on these results, ACOM-TEM observations were made after different strain increments:

- Firstly after $10 \%$ of macroscopic tensile strain, where the strain hardening rate is decreasing and the HEXRD data does not reveal the occurrence of a strain induced phase transformation.

- Secondly after $20 \%$ of macroscopic tensile strain, which corresponds to the minimum of strain hardening rate and to the point where a significant fraction of austenite has been transformed into martensite.

- And finally, at fracture strain.

Figure 2 shows an ACOM-TEM phase map after $10 \%$ of tensile plastic strain, within an austenite grain. At this stage, almost all the plastic deformation has occurred by dislocation glide. The index quality that is superimposed to the phase map strongly suggest a planar slip in austenite, which precedes the apparition of some localized areas of $\varepsilon$-martensite, in the form of very thin bands, several $\mu \mathrm{m}$ long and barely $100 \mathrm{~nm}$ thick. The pole figures (see supplementary material, Figure S2) show, as expected, an orientation relationship close to Shoji-Nishiyama $(\mathrm{S}-\mathrm{N}):(111)_{\gamma} \|(0001)_{\varepsilon}$ and $[10 \overline{1}]_{\gamma} \|(11 \overline{2} 0)_{\varepsilon}$.

Figure 3 shows an ACOM-TEM phase map after $20 \%$ plastic strain, in a formerly mainly austenitic region, containing initially also a small elongated ferrite grain as pointed out by the arrow. The ACOM phase map shows clearly several banded regions of $\varepsilon$-martensite and, at their intersections, islands of $\alpha^{\prime}$-martensite that are growing inside the austenite matrix. This microstructure appears to be quite heterogeneously distributed in the material. The austenite at the top right of the image still presents mostly only one variant of $\varepsilon$-martensite with almost no trace of $\alpha$ '-martensite, whereas in 
the centre a large amount of $\alpha^{\prime}$-martensite has already formed. The orientation map as well as a higher resolution phase map with associated pole figures are provided as supplementary material (see Figures S3 ad S4). These data show that at after 20\% macroscopic tensile strain, most $\alpha$ 'martensite has appeared as one variant, satisfying the Kurdjumov-Sachs (K-S) and NishiyamaWassermann $(\mathrm{N}-\mathrm{W})$ orientation relationships with austenite.

Figure 4 shows an ACOM-TEM phase map acquired at fracture strain. It must be pointed out that this orientation mapping technique is particularly well suited to characterize highly deformed materials as the indexing quality is almost insensitive to a high density of dislocations. This map was acquired in a formerly austenitic grain, close to a ferrite grain visible at the top of the map. Here, a large fraction of the austenite has transformed into martensite, in agreement with the HEXRD results that give a transformed fraction of about $60 \%$. A very low fraction of $\varepsilon$-martensite can be observed, showing that the formation of this phase was mostly restricted to the initial stages of the phase transformation process, so that when $\alpha^{\prime}$-martensite has nucleated it can grow within the remaining austenite. The respective orientation maps of ferrite+martensite and austenite corresponding to this phase map are provided in supplementary material (Figure S5). Based on these maps, one can evidence the presence of large misorientations within the phases, including $\alpha$ 'martensite, which suggests that this phase was deformed plastically after its formation.

These results present for the first time the mechanisms for SIM at the high resolution permitted by the ACOM-TEM technique, and without the issues of poor indexing due to highly deformed microstructures. They confirm that SIM occurs following mechanisms previously evidenced in austenitic steels [16] by conventional TEM and in Ni-free Mn-rich DSS [3] by EBSD.

\section{Influence of two-phase microstructure}

TEM phase mapping in the previous section allowed to unravel the sequence of deformation mechanisms leading to the SIM in the Duplex alloy. Now, we will examine the role of the twophase initial microstructure, in order to elucidate the influence of the presence of ferrite on the transformation of austenite. For this purpose, two model alloys, respectively an austenitic and a ferritic alloy, have been elaborated with chemical compositions as close as possible from those of the two phases constituting the Duplex alloy. Their composition is given in Table 3. The last line of Table 3 shows that a hypothetical mixture of these two alloys would match closely the composition of the Duplex alloy. In order to obtain a realistic mechanical behaviour for these two alloys when compared to that of the Duplex alloy, it is necessary to satisfy two conditions: (i) they should be as close as possible from single phase austenitic and ferritic alloy, thus not presenting a significant fraction of other phases; and (ii) they should have a grain size similar to that found in the duplex alloy of interest.

Equilibrium thermodynamic calculations with Thermo-Calc ${ }^{\circledR}$ showed that the ferritic alloy is $100 \%$ ferritic from $1050^{\circ} \mathrm{C}$ to the liquid phase. A $100 \%$ ferritic microstructure was successfully achieved by quenching from temperatures above $1050^{\circ} \mathrm{C}$. However, the more challenging part was to obtain a small grain size, since grain growth kinetics is relatively rapid at this temperature. The final microstructure was finally obtained by a recrystallization treatment consisting of a $50 \%$ cold rolling reduction followed by a heat treatment of 5 minutes at $1090^{\circ} \mathrm{C}(2 \mathrm{~min}$ were required to reach this temperature) followed by a water quench. This heat treatment resulted in an average grain size of about $80 \mu \mathrm{m}$ as illustrated in Figure 5a, still larger than that of the duplex microstructure (roughly $20 \mu \mathrm{m}$ ) but of the right order of magnitude.

The processing of the austenitic alloy turned out to be more complicated, because after solidification the ingot exhibited $13 \%$ of residual $\delta$-ferrite. Thermo-Calc $₫$ calculations showed that this alloy is supposed to be $100 \%$ austenitic only in the range $1050-1090^{\circ} \mathrm{C}$. Below this temperature, the $\mathrm{Cr}_{2} \mathrm{~N}$ phase forms and above one finds some ferrite. Ferrite regression was thus carried out at $1090^{\circ} \mathrm{C}$, i.e. the highest temperature at which the microstructure is fully austenitic. For short ageing times at this temperature, the grain size was small, about $20 \mu \mathrm{m}$, but the ferrite fraction still large $(\sim 6 \%)$. On the opposite large grain size and low residual ferrite fraction were 
found for long ageing times $(150 \mu \mathrm{m}, 3.5 \%$ after $15 \mathrm{~h})$. The best compromise was found to be a duration of $8 \mathrm{~h}$ resulting in a ferrite fraction of only $3.6 \%$ and a grain size of $60 \mu \mathrm{m}$, as illustrated by the micrograph in Figure 5b.

The tensile stress-strain responses for the three alloys, namely the duplex alloy and its two components: the ferritic and austenitic alloys having the same composition as the phases found in the duplex steel, are shown in Figure 6a. The tensile behaviour of the duplex alloy lies in between that of the ferritic and austenitic alloy in the range of plastic strains where the constitutive behaviour of all three materials is available. One has to keep in mind that it is difficult to exactly assess the behaviour of ferrite at large strains because the ferritic alloy has a low ductility and fails below $10 \%$ true strain. Figure $6 \mathrm{~b}$ shows the strain hardening rate behaviour of the ferritic, austenitic and duplex alloys, together with the fractions of austenite transformed into martensite, determined by in-situ HEXRD. These results show that the ferritic alloy has a very low strain hardening rate, leading to premature failure. On the other hand, the evolution of strain hardening rate is similar in both the duplex and austenitic steel, with a maximum strain hardening rate emerging shortly after the maximum transformation rate. The higher strain hardening rate of the austenitic alloy as compared to the duplex alloy can be explained by the conjunction of two effects:

- a higher fraction of initial austenite: $100 \%$ vs. $50 \%$

- and a faster kinetics of transformation of this austenite with strain.

This difference shows that the behaviour of the austenitic alloy cannot be directly transposed to the duplex alloy beyond the qualitative similarity of the phase transformation behaviour. The difference in kinetics may be due to two reasons (at least). First, the transformation in the duplex alloy could be hindered by the presence of ferrite, or by the smaller grain size in the duplex alloy in comparison with that of the austenitic alloy, as evidenced by other authors in $[42,43]$. Second, a difference could also arise between the two materials, namely the strengthening effect of the strain-induced martensitic transformation could be different between the austenitic and duplex alloys. In order to test this assumption, an analytical mechanical model describing the tensile stress-strain behaviour for the austenitic alloy from the martensite transformation rate has been developed. This rather simple model allows to evaluate if this behaviour could be transposed to capture the duplex alloy tensile response behaviour.

To describe the evolution of transformed fraction with strain, a simple Olson and Cohen model [15] was fitted to the in-situ HEXRD data with the following equation:

$$
f_{M}=1-\exp \left(-B[1-\exp (-A \varepsilon)]^{n}\right)
$$

$A$ being the rate of formation of $\varepsilon$ martensite bands, $B$ the frequency of nucleation of $\alpha^{\prime}$-martensite, and $n$ being the exponent relating the number of bands to the number of their intersections. $n$ was kept constant at 4.5, following the original suggestion from Olson and Cohen [15] while $A$ and $B$ have been identified based on the kinetic determined from the HEXRD data. The resulting fit is shown in Figure 6b. For the austenitic alloy both parameters were determined to be equal respectively to $A=4.48$ and $B=2.61$. For the duplex alloy both parameters were estimated: $A=2.72$ and $B=3.02$. Thus, the main difference between the duplex and austenitic steel appears to be the $A$ parameter illustrating the initial tendency to $\varepsilon$ martensite formation.

In parallel, the stress-strain curve for the austenite was fitted in the initial part by a simple powerlaw: $\sigma=\sigma_{y}+K \varepsilon^{n}$ where $\sigma_{y}$ is the yield stress, $K$ a constant and $n$ the strain exponent. The data of the austenitic alloy were used only to a plastic strain of about $8 \%$ where the phase transformation starts. The adjusted fit is shown in supplementary materials (Figure S6), resulting in the following set of parameters: $\sigma_{y}=275 \mathrm{MPa}, K=908 \mathrm{MPa}, n=0.41$. The additional contribution to strength arises from the presence of martensite and in particular from its interaction with austenite. To describe the stress-strain response of the transforming alloy, we used a self-consistent homogenization scheme described in details in [44]. The constitutive law of martensite was adjusted so that the full model would give a good agreement with the experimental stress-strain curve. The obtained agreement is excellent, as shown in Figure 6a, with a constitutive law of martensite following a power law with $\sigma_{y}=700 \mathrm{MPa}, K=3100 \mathrm{MPa}$ and $n=0.5$. Such a 
constitutive law, with a high strain hardening exponent, may be seen as the result of a dynamic refinement of the microstructure during the phase transformation, and reflects the fact that martensite can be deformed for large strains after it has been first formed. This was further exemplified by TEM observations discussed in section 3 .

Based on this identification procedure, the behaviour of the Duplex alloy has been successfully modelled as well. The additional remaining ingredient to fully describe the behaviour of the Duplex steel when compared to the austenitic steel is the constitutive law of the ferritic phase. This was achieved using the stress-strain curve of the ferritic alloy. Similarly, a power law was used, fitted over the available strain range for the ferritic alloy (see supplementary material, Figure S6). The fit results in the following set of parameters: $\sigma_{y}=500 \mathrm{MPa}, K=514 \mathrm{MPa}, n=0.47$. Finally, the same self-consistent homogenization calculation was applied to the duplex alloy, now including the behaviour of three phases, namely ferrite, austenite, and martensite. For martensite, the same constitutive law as the one used for describing the austenitic alloy was used. The result of the calculation is shown in Figure 6a along with the experimental stress-strain curves. The agreement with the experimental data is excellent, meaning that the relationship between martensite fraction and mechanical strengthening is the same, within uncertainty, in the austenitic and duplex alloys.

\section{Role of alloy composition and pre-straining}

The role of the strain-induced martensitic transformation on controlling the level of strain hardening rate was investigated and discussed in section 4 . The next step in our approach was to evaluate how changing the kinetics of this transformation (i.e. the strain dependence of transformed fraction) results in different mechanical properties in terms of strength / uniform elongation balance. The influence of two parameters on the alloy's stress-strain curves will be evaluated by:

- changing the alloy composition to play directly on the degree of austenite instability without changing drastically the yield strength,

- or applying a pre-deformation by rolling, which should increase the yield strength, while resulting in a different fraction of transformed martensite, yet lower than that obtained for a same strain level in tension because of the higher level of hydrostatic stress experienced in rolling.

The composition of the four alloys investigated in this work (labelled A to D, alloy C being close to the duplex alloy studied in sections 3 and 4) has been given in Table 1. In order to reach a different level of instability for the austenite phase, while maintaining a fraction of both phases close to 50\%, the contents of $\mathrm{Ni}$ and $\mathrm{N}$ were varied in opposite directions with some minor change of $\mathrm{Cr}$, while maintaining the carbon content constant. Figure 7 shows optical micrographs of the initial microstructures of the four alloys. In the initial conditions, i.e. before straining, they appear to be very similar in terms of phase morphology and grain size. As a preliminary investigation, the phase fractions before tensile testing (in the initial state and after pre-deformation by rolling) have been measured by magnetic measurements [45]. Those measurements were performed using the withdrawal method in accordance to IEC 60404-14, and using Voboril's formula [46] so as to estimate the magnetic saturation of the ferromagnetic phase from its chemical composition. The volume fraction of ferrite was found to be approximately $50 \%$ in alloys B, C and D, and closer to 60 $\%$ in alloy $\mathrm{A}$. The initial measurements are consistent with the ferrite fractions calculated by Thermocalc $\AA$ and will be shown to be consistent with the more quantitative measurements made by HEXRD. The evolution of the ferrite fractions with pre-strain shows a relatively small evolution in alloys A, B and C. It means that during pre-deformation, the level of strain-induced martensite formation is within experimental uncertainty. However, alloy D exhibits a strong evolution when pre-straining increases, showing that its austenitic phase is much more instable.

\section{5.a Stress-strain curves}


Figure 9 presents the stress-strain curves of the four alloys investigated with the three different initial states, namely undeformed, $10 \%$ and $20 \%$ plastically deformed. The four alloys exhibit a very different tensile behaviour. Alloy A shows a typical stress-strain curve of an alloy without TRIP effect. Although it has the highest yield strength, its uniform elongation is low and predeformation reduces further its capacity for tensile deformation. On the other hand, alloy D presents an S-shaped tensile curve typical of a significant TRIP effect, which seems triggered at relatively low strains (about 0.1 true strain). Even after pre-deformation this behaviour is still observed, showing that the transformation of austenite into martensite was not completed during the predeformation by rolling, in agreement with the results of Figure 8. The resulting true stress at necking and uniform elongation are both higher than that of alloy A. Finally, in between, Alloys B and $\mathrm{C}$ show very similar results, namely an S-shaped stress-strain curve, but less pronounced in comparison with that of alloy $\mathrm{D}$, whether in the undeformed state or after pre-deformation. These two alloys (B and $\mathrm{C}$ ) exhibit the best compromise between elongation and true stress at necking, with values of $0.45 / 1100 \mathrm{MPa}$ for the undeformed material, and $0.3 / 1200 \mathrm{MPa}$ for the $20 \%$ predeformed material. Table 4 summarizes the data obtained from the stress-strain curves until fracture in terms of yield stress (at $0.2 \%$ offset strain), engineering ultimate tensile strength (UTS) and engineering fracture strain. As will be shown below, this optimal behaviour in alloys $\mathrm{B}$ and $\mathrm{C}$ is made possible by a progressive plasticity induced transformation occurring over a wide range of strain.

\section{5.b. Strain hardening rate and phase fractions}

Figure 10 presents for all 12 cases the evolution with strain of the true stress, the strain hardening rate defined as $\theta=\mathrm{d} \sigma / \mathrm{d} \varepsilon$ as well as the fraction of BCC phase (ferrite + martensite) measured insitu by HEXRD.

For alloy A, the HEXRD results show without any doubt that there is no evolution of the phase fractions during the tensile tests, and this was assessed whatever the level of pre-deformation. The onset of necking occurs when the true stress and strain hardening rates are equal, obeying strictly to the Considère criterion. The strain hardening rate continuously decreases, in line with what is expected from a non-phase transforming microstructure. For alloys $\mathrm{B}$ and $\mathrm{C}$, the fraction of $\mathrm{BCC}$ phase is stable during the first 0.15 true strain, showing the absence of austenite transformation into $\alpha$ ' martensite, and then increases slowly from 50 to $80 \%$ during subsequent straining. The strain hardening rate is very well correlated with the evolution of the phase fraction: the initial decrease of strain hardening rate is stopped as soon as the martensite fraction starts to increase significantly. Another interesting feature revealed by these data is that the excellent tensile properties of alloy $\mathrm{B}$ and $\mathrm{C}$ clearly arise from the fact that the rate of phase transformation is just large enough so that the strain hardening rate remains above the value of true stress even for large strains. The final decrease of the strain hardening rate below the true stress, which triggers necking, seems to be related to a saturation of the rate of austenite decomposition. In alloy $\mathrm{D}$, the plasticity induced transformation occurs much earlier, at around 0.05 true strain, and then progresses more rapidly. The austenite fraction reaches almost zero at the end of the tensile test, which results in a drastic decrease of the strain hardening rate and thus necking. Earlier during the tensile test, the difference between the values of strain hardening rate and true stress is unnecessarily large, as keeping a large strain hardening rate capacity to large strains is necessary to further delay necking.

The effect of pre-deformation by rolling also deserves to be discussed in more details. Overall, predeformation decreases the uniform elongation, increases the yield strength and shifts the phase transformation to earlier strains. However, the magnitude of this shift appears to be much smaller than the level of pre-deformation itself. This is better reflected in Figure 11 which presents the evolution of phase fractions for the four alloys and for the different levels of pre-strain. The shift between the curves displayed in Figure 11 is in all cases lower than the level of pre-deformation, typically a shift of $10 \%$ for a pre-deformation of $20 \%$. 


\section{Discussion}

It is now well recognised that the strength / elongation compromise in duplex stainless steels can be effectively optimised by playing on the stability of austenite, see e.g. [3,5]. For a given alloy composition, the mechanical behaviour depends further on the details of the heat treatment, since high temperature annealing controls the proportions of austenite and ferrite and consequently the partitioning of alloying elements [6,19]. Lower temperature annealing can promote formation of carbides that both increase the yield strength and change the austenite stability by modifying its chemical composition [6].

Although classical lean-DSS contain a significant amount of $\mathrm{Ni}$ (of the order of $4 \mathrm{wt} \%$ ), alloys have been recently developed with $\mathrm{Mn}$ as an austenite stabilizer instead, resulting in extremely good mechanical properties [3]. However, these low Ni lean-DSS present a lower resistance to fracture and long term thermal ageing [7,8]. Thus, there is room for mechanical properties optimization within the medium-Ni compositions, which has been the strategy followed by the present study. Our results show that adjusting the N/Ni ratio is an effective way to control the austenite stability while maintaining equal proportions of ferrite and austenite. A wide range of mechanical behaviour have been obtained, from a material fully stable at room temperature (alloy A) to a very unstable material containing an austenite which transforms almost totally during a tensile test (alloy D). The intermediate compositions, namely alloys $\mathrm{B}$ and $\mathrm{C}$, provide an optimal level of stability. In the duplex alloy investigated in section 3 and very similar to alloy $\mathrm{C}$, the TEM observations reported here evidence the two-stage transformation mechanism to $\alpha$ '-martensite through the formation of thin bands of $\varepsilon$-martensite. The martensite is shown to be highly deformable, resulting in large orientation gradients in all phases at fracture strain. The study of the two materials of the same composition as the constituting phases of the duplex alloy (austenite and ferrite) brings some insights on the role of the two-phase microstructure. Our results demonstrate that the relationship between transformed phase fraction and flow stress is identical in the austenitic and in the duplex alloy. Indeed, a single mechanical model, based on the phase transformation kinetics determined by in-situ HEXRD, describes equally well the two tensile stress-strain curves with only one set of constitutive laws for the three phases present, although one has to bear in mind that this model does not take explicitly into account the presence of $\varepsilon$-martensite. However, the kinetics of phase transformation turns out to be faster in the austenitic alloy as compared to the duplex alloy. While this may be due to a difference in grain size following the evidence given in [42,43], it is not possible at this time to exclude some constraining effect of ferrite on the phase transformation in austenite within the duplex structure, which could be related to the lower tendency for strain localization in ferrite. To elucidate this peculiar point, a similar methodology should be carried out with a common grain size in respectively the fully austenitic steel and the duplex steel. Since it has proven difficult to decrease the grain size of the austenitic alloy, one could increase that of the duplex alloy instead. From the point of view of the ferrite phase, however, the beneficial effect of the presence of austenite in the DSS is very clear, since the purely ferritic alloy has very limited ductility.

Last, it is of interest to evaluate the influence of the formation of martensite on the microscopic distribution of plastic deformation in the complex microstructure consisting of ferrite, austenite and forming martensite, since a strong strain partitioning may lead to damage accumulation and thus play a role in post-necking strain. In a recent publication [28], we have shown that in an alloy exhibiting a high degree of instability of the austenite such as alloy $\mathrm{D}$, the martensitic transformation resulted in an increasing partitioning of plastic strain within the softest phase, namely the initial ferrite, whereas the combination of residual austenite and martensite were 
subjected to lower levels of plastic deformation ${ }^{1}$. Using the same protocol as described in [28], the microscopic distributions of plastic deformation have been measured in alloys $\mathrm{A}$ and $\mathrm{D}$ for different levels of strain. Figure 12 shows that these two alloys behave very differently in terms of distribution of microscale plastic strains. While alloy D shows a tendency for strain partitioning within the ferrite, alloy A presents an almost perfect equi-distribution of average strain in both ferrite and austenite. This can be further verified by plotting the distribution of strain values obtained from the micro-DIC maps in the two alloys for different values of plastic strain, as shown in Figures 12 (c), (d), (e) and (f). While, in alloy A, the distribution of strain is exactly the same in ferrite and in the regions encompassing austenite and strain-induced martensite, alloy D shows large variations with ferrite deforming to much larger levels due to the high hardness of the forming strain-induced martensite.

A characteristic feature of these alloys where the strain hardening rate provided by the strain induced transformation is used to improve the ductility, is necessarily their relatively low yield strength. Our results show that tailoring the compromise between yield strength, UTS and elongation can be achieved by pre-deformation, which improves the yield strength, of course at some expense of the UTS / ductility compromise. This is best observed when summarizing the data of Table 4 in two graphs, one describing the yield strength / fracture strain compromise, and the other the UTS / fracture strain compromise, as shown in Figure 13. The principle of a TRIP-DSS is that the strain-induced transformation should be triggered as late as possible in order to provide strain hardening at large strains. Pre-deformation is detrimental in this respect insofar it triggers some strain-induced transformation before the beginning of the tensile test. However, our results show that the shift in strain of the transformed fraction during the tensile test is lower than expected from the pre-strain. This can be related to the change in deformation mode, namely pre-deformation was achieved by rolling, where the hydrostatic stress is compressive, opposite to that of the tensile test, where it is under uniaxial tension. Since there is a positive volume change associated to the strain-induced transformation, it is expected that rolling results in a smaller transformed fraction as compared to a tensile test for an equivalent level of strain [47]. Of course, other parameters may play a role when changing the strain path, such as texture effects, which have been shown to play a role on the strain-induced transformation [20].

A way to suppress the phase transformation that occurs during pre-deformation by cold-rolling is to perform pre-deformation at warm temperature, where austenite is much more stable. In order to test this idea, a slightly modified version of alloy D, namely alloy E, was finally cast with a chemical composition equivalent to alloy $\mathrm{D}$ for all elements except Nitrogen whose content was adjusted at $0.067 \mathrm{wt} \%$. It was processed likewise the other alloys, and pre-deformed $20 \%$ by rolling either at room temperature or at $200^{\circ} \mathrm{C}$. Figure 14 shows the resulting tensile stress-strain curves. The colddeformed material shows a stress-strain curve characteristic of a material where a significant amount of phase transformation has already taken place, while the warm rolled material exhibits a long Lüders-like plateau before the high strain hardening rate related to the phase transformation begins. This shows that warm pre-deformation is an effective way to improve the alloy's yield strength while retaining the phase transformation potential for the desired final tensile properties.

\section{Conclusions}

This study has systematically investigated the plastic deformation mechanisms in duplex stainless steels showing a transformation-induced martensitic transformation, their relationship with stressstrain curves and the effect of alloy composition and pre-deformation on the mechanical behaviour. The main conclusions can be drawn as follows.

\footnotetext{
1 Note that the differentiation of strain between the phases is made from chemical contrast in backscattered SEM images, so that it is not possible to differentiate strain between austenite and martensite using this technique.
} 
- In these alloys, strain-induced martensitic transformation occurs by a two-step mechanism involving the formation of $\varepsilon$-martensite followed by the formation of $\alpha$ '-martensite at the intersection of $\varepsilon$-martensite bands.

- The kinetics of strain-induced transformation in the duplex alloy is similar but slower as compared to that occurring in an austenitic alloy having the same composition than the austenitic phase of the duplex alloy.

- A rather simple mechanical model was able to capture both the stress-strain behaviour of the austenitic and duplex alloys from the experimentally measured martensite fractions, using only one set of constitutive laws for the three materials involved: austenite, ferrite, and martensite.

- Adjusting the alloy chemistry by playing with the $\mathrm{Ni} / \mathrm{N}$ ratio or the thermomechanical path by tuning the level of pre-deformation is an effective way to tailor the yield strength / ultimate tensile strength / elongation compromise of DSSs. The optimal range of $\mathrm{Ni} / \mathrm{N}$ ratio, given the content in other alloying elements of our steels, lies between the alloys B and C.

- The austenite stability is the key parameter for the control of the plastic behaviour. When it is properly adjusted, the strain hardening rate can remain slightly above the true stress value up to large strains and thus promote a good combination of ultimate tensile strength and elongation.

\section{Acknowledgements}

This work was performed within the framework of the Center of Excellence of Multifunctional Architectured Materials "CEMAM" n'AN-10-LABX-44-01 funded by the "Investments for the Future Program". The PTA (Plateforme Technologie Amont) located in Grenoble is gratefully acknowledged for giving access to the Au deposition facilities. The technical staff of ID15 beamline at ESRF, particularly T. Buslaps, is gratefully acknowledged for support during the experiments. Dr. H. Naser is thanked for help during the HEXRD experiments. Dr. G. Geandier of Institut Jean Lamour, Nancy, France is thanked for support with the Fullprof software.

\section{References}

[1] J. Charles, Duplex stainless steels - a review after DSS '07 held in Grado, Steel Res. Int. 79 (2008) 455-465. doi:10.2374/SRI08SP063-79-2008-455.

[2] K.H. Lo, C.H. Shek, J.K.L. Lai, Recent developments in stainless steels, Mater. Sci. Eng. RRep. 65 (2009) 39-104. doi:10.1016/j.mser.2009.03.001.

[3] C. Herrera, D. Ponge, D. Raabe, Design of a novel Mn-based 1 GPa duplex stainless TRIP steel with 60\% ductility by a reduction of austenite stability, Acta Mater. 59 (2011) 4653-4664. doi:10.1016/j.actamat.2011.04.011.

[4] J.Y. Choi, J.H. Ji, S.W. Hwang, K.-T. Park, TRIP aided deformation of a near-Ni-free, Mn$\mathrm{N}$ bearing duplex stainless steel, Mater. Sci. Eng. -Struct. Mater. Prop. Microstruct. Process. 535 (2012) 32-39. doi:10.1016/j.msea.2011.12.037.

[5] J.Y. Choi, J.H. Ji, S.W. Hwang, K.-T. Park, Effects of nitrogen content on TRIP of Fe-20Cr$5 \mathrm{Mn}-\mathrm{xN}$ duplex stainless steel, Mater. Sci. Eng. -Struct. Mater. Prop. Microstruct. Process. 534 (2012) 673-680. doi:10.1016/j.msea.2011.12.025.

[6] Q. Ran, Y. Xu, J. Li, J. Wan, X. Xiao, H. Yu, L. Jiang, Effect of heat treatment on transformation-induced plasticity of economical Cr19 duplex stainless steel, Mater. Des. 56 (2014) 959-965. doi:10.1016/j.matdes.2013.12.019.

[7] M. Liljas, P. Johansson, H.-P. Liu, C.-O.A. Olsson, Development of a Lean Duplex Stainless Steel, Steel Res. Int. 79 (2008) 466-473. doi:10.1002/srin.200806154.

[8] G. Straffelini, S. Baldo, I. Calliari, E. Ramous, Effect of Aging on the Fracture Behavior of Lean Duplex Stainless Steels, Metall. Mater. Trans. -Phys. Metall. Mater. Sci. 40A (2009) 26162621. doi:10.1007/s11661-009-9968-0. 
[9] Y. Jiang, H. Tan, Z. Wang, J. Hong, L. Jiang, J. Li, Influence of Creq/Nieq on pitting corrosion resistance and mechanical properties of UNS S32304 duplex stainless steel welded joints, Corros. Sci. 70 (2013) 252-259. doi:10.1016/j.corsci.2013.01.037.

[10] E. Medina, J.M. Medina, A. Cobo, D.M. Bastidas, Evaluation of mechanical and structural behavior of austenitic and duplex stainless steel reinforcements, Constr. Build. Mater. 78 (2015) 17. doi:10.1016/j.conbuildmat.2015.01.008.

[11] Z. ZHANG, Q. RAN, Y. XU, X. YU, D. JIANG, X. XIAO, A New Series of Mo-free 21. 5Cr-3. 5Ni-x W-0. 2N Economical Duplex Stainless Steels, J. Iron Steel Res. Int. 21 (2014) 69-75. doi:10.1016/S1006-706X(14)60011-X.

[12] L. Remy, A. Pineau, Twinning and strain-induced F.C.C. $\rightarrow$ H.C.P. transformation in the Fe-Mn-Cr-C system, Mater. Sci. Eng. 28 (1977) 99-107. doi:10.1016/0025-5416(77)90093-3.

[13] M. Moallemi, A. Zarei-Hanzaki, M. Eskandari, A. Burrows, H. Alimadadi, Comprehensive Deformation Analysis of a Newly Designed Ni-Free Duplex Stainless Steel with Enhanced Plasticity by Optimizing Austenite Stability, Metall. Mater. Trans. -Phys. Metall. Mater. Sci. 48A (2017) 3675-3691. doi:10.1007/s11661-017-4122-x.

[14] K. Spencer, J.D. Embury, K.T. Conlon, M. Véron, Y. Bréchet, Strengthening via the formation of strain-induced martensite in stainless steels, Mater. Sci. Eng. A. 387-389 (2004) 873881. doi:10.1016/j.msea.2003.11.084.

[15] G.B. Olson, M. Cohen, Kinetics of Strain-Induced Martensitic Nucleation, Metall. Trans. A. 6 (1975) 791-795. doi:10.1007/BF02672301.

[16] T.-H. Lee, H.-Y. Ha, J.-Y. Kang, J. Moon, C.-H. Lee, S.-J. Park, An intersecting-shear model for strain-induced martensitic transformation, Acta Mater. 61 (2013) 7399-7410. doi:10.1016/j.actamat.2013.08.046.

[17] E.-Y. Kim, W. Woo, Y.-U. Heo, B. Seong, J. Choi, S.-H. Choi, Effect of kinematic stability of the austenite phase on phase transformation behavior and deformation heterogeneity in duplex stainless steel using the crystal plasticity finite element method, Int. J. Plast. 79 (2016) 48-67. doi:10.1016/j.ijplas.2015.12.009.

[18] Y. Li, W. Li, J.C. Hu, H.M. Song, X.J. Jin, Compatible strain evolution in two phases due to epsilon martensite transformation in duplex TRIP-assisted stainless steels with high hydrogen embrittlement resistance, Int. J. Plast. 88 (2017) 53-69. doi:10.1016/j.ijplas.2016.09.012.

[19] N. Saenarjhan, J.-H. Kang, S.C. Lee, S.-J. Kim, Influence of annealing temperature on deformation behavior of 329LA lean duplex stainless steel, Mater. Sci. Eng. -Struct. Mater. Prop. Microstruct. Process. 679 (2017) 531-537. doi:10.1016/j.msea.2016.10.062.

[20] J.-Y. Kang, H. Kim, K.-I. Kim, C.-H. Lee, H.N. Han, K.-H. Oh, T.-H. Lee, Effect of austenitic texture on tensile behavior of lean duplex stainless steel with transformation induced plasticity (TRIP), Mater. Sci. Eng. -Struct. Mater. Prop. Microstruct. Process. 681 (2017) 114-120. doi:10.1016/j.msea.2016.11.001.

[21] Y. Zhao, W. Zhang, X. Liu, Z. Liu, G. Wang, Development of TRIP-Aided Lean Duplex Stainless Steel by Twin-Roll Strip Casting and Its Deformation Mechanism, Metall. Mater. Trans. Phys. Metall. Mater. Sci. 47A (2016) 6292-6303. doi:10.1007/s11661-016-3771-5.

[22] Y. Zhao, W. Zhang, Z. Liu, G. Wang, Development of an easy-deformable Cr21 lean duplex stainless steel and the effect of heat treatment on its deformation mechanism, Mater. Sci. Eng. A. 702 (2017) 279-288. doi:10.1016/j.msea.2017.07.020.

[23] B. Guo, Q. Zhang, L. Chen, X. Guo, N. Li, X. Liu, M. Jin, Influence of annealing temperature on the strain-hardening behavior of a lean duplex stainless steel, Mater. Sci. Eng. A. 722 (2018) 216-224. doi:10.1016/j.msea.2018.03.027.

[24] J.Y. Choi, J.H. Ji, S.W. Hwang, K.-T. Park, Strain induced martensitic transformation of $\mathrm{Fe}-20 \mathrm{Cr}-5 \mathrm{Mn}-0.2 \mathrm{Ni}$ duplex stainless steel during cold rolling: Effects of nitrogen addition, Mater. Sci. Eng. A. 528 (2011) 6012-6019. doi:10.1016/j.msea.2011.04.038.

[25] Y.F. Shen, L.N. Qiu, X. Sun, L. Zuo, P.K. Liaw, D. Raabe, Effects of retained austenite volume fraction, morphology, and carbon content on strength and ductility of nanostructured TRIPassisted steels, Mater. Sci. Eng. -Struct. Mater. Prop. Microstruct. Process. 636 (2015) 551-564. 
doi:10.1016/j.msea.2015.04.030.

[26] J.Y. Choi, J. Lee, K. Lee, J.-Y. Koh, J.-H. Cho, H.N. Han, K.-T. Park, Effects of the strain rate on the tensile properties of a TRIP-aided duplex stainless steel, Mater. Sci. Eng. -Struct. Mater. Prop. Microstruct. Process. 666 (2016) 280-287. doi:10.1016/j.msea.2016.04.047.

[27] Y.-S. Jung, Y.-K. Lee, Effect of pre-deformation on the tensile properties of a metastable austenitic steel, Scr. Mater. 59 (2008) 47-50. doi:10.1016/j.scriptamat.2008.02.019.

[28] A. Lechartier, G. Martin, S. Comby, F. Roussel-Dherbey, A. Deschamps, M. Mantel, N. Meyer, M. Verdier, M. Veron, Influence of the Martensitic Transformation on the Microscale Plastic Strain Heterogeneities in a Duplex Stainless Steel, Metall. Mater. Trans. A. 48 (2017) 20 25. doi:10.1007/s11661-016-3858-z.

[29] N. Jia, Z.H. Cong, X. Sun, S. Cheng, Z.H. Nie, Y. Ren, P.K. Liaw, Y.D. Wang, An in situ high-energy X-ray diffraction study of micromechanical behavior of multiple phases in advanced high-strength steels, Acta Mater. 57 (2009) 3965-3977. doi:10.1016/j.actamat.2009.05.002.

[30] C.U. Jeong, W. Woo, J.Y. Choi, S.-H. Choi, Effect of kinematic stability of initial orientation on deformation heterogeneity and ductile failure in duplex stainless steel during uniaxial tension, Acta Mater. 67 (2014) 21-31. doi:10.1016/j.actamat.2013.12.020.

[31] C. Gauss, I.R. Souza Filho, M.J.R. Sandim, P.A. Suzuki, A.J. Ramirez, H.R.Z. Sandim, In situ synchrotron X-ray evaluation of strain-induced martensite in AISI 201 austenitic stainless steel during tensile testing, Mater. Sci. Eng. A. 651 (2016) 507-516. doi:10.1016/j.msea.2015.10.110.

[32] W. Woo, J. Kim, E.-Y. Kim, S.-H. Choi, V. Em, D.S. Hussey, Multi-scale analyses of constituent phases in a trip-assisted duplex stainless steel by electron backscatter diffraction, in situ neutron diffraction, and energy selective neutron imaging, Scr. Mater. 158 (2019) 105-109. doi:10.1016/j.scriptamat.2018.08.040.

[33] K. Nohara, Y. One, N. Ohashi, Composition and grain size dependencies of strain-induced martensitic transformation in metastable austenitic stainless steels, J. Iron Steel Inst. Jpn. 63 (1977) 212-222.

[34] T.J. Angel, Formation of Martensite in Austenitic Stainless Steels, J. Iron Steel Inst. 177 (1954) 165-174.

[35] E.F. Rauch, M. Veron, S. Nicolopoulos, D. Bultreys, Orientation and phase mapping in TEM microscopy (EBSD-TEM like): applications to materials science, Solid State Phenom. 186 (2012) 13-15.

[36] E.F. Rauch, M. Veron, Automated crystal orientation and phase mapping in TEM, Mater. Charact. 98 (2014) 1-9. doi:10.1016/j.matchar.2014.08.010.

[37] C. Frontera, J. Rodriguez-Carvajal, FULLPROF as a new tool for flipping ratio analysis, Phys. B-Condens. Matter. 335 (2003) 219-222. doi:10.1016/S0921-4526(03)00241-2.

[38] C. Frontera, J. Rodriguez-Carvajal, FULLPROF as a new tool for flipping ratio analysis: further improvements, Phys. B-Condens. Matter. 350 (2004) E731-E733.

doi:10.1016/j.physb.2004.03.192.

[39] E. Heripre, M. Dexet, J. Crepin, L. Gelebart, A. Roos, M. Bornert, D. Caldemaison, Coupling between experimental measurements and polycrystal finite element calculations for micromechanical study of metallic materials, Int. J. Plast. 23 (2007) 1512-1539.

doi:10.1016/j.ijplas.2007.01.009.

[40] M. Bornert, F. Vales, H. Gharbi, D.N. Minh, Multiscale Full-Field Strain Measurements for Micromechanical Investigations of the Hydromechanical Behaviour of Clayey Rocks, Strain. 46 (2010) 33-46.

[41] G. Martin, D. Caldemaison, M. Bornert, C. Pinna, Y. Brechet, M. Veron, J.D. Mithieux, T. Pardoen, Characterization of the High Temperature Strain Partitioning in Duplex Steels, Exp.

Mech. 53 (2013) 205-215. doi:10.1007/s11340-012-9628-y.

[42] C.-S. Yoo, Y.-M. Park, Y.-S. Jung, Y.-K. Lee, Effect of grain size on transformationinduced plasticity in an ultrafine-grained metastable austenitic steel, Scr. Mater. 59 (2008) 71-74. doi:10.1016/j.scriptamat.2008.02.024.

[43] C.W. Sinclair, D. Marechal, J.D. Mithieux, The effect of grain size on the mechanical 
response of a metastable austenitic stainless steel, in: J. Chone, J.D. Guerin, P. Quaegebeur (Eds.), Ja 2013 - Journees Annu. Sf2m 2013 Sf2m Annu. Meet. 2013, E D P Sciences, Cedex A, 2013: p. UNSP 01010.

[44] A. Lechartier, Influence of strain induced martensitic transformation on the mechanical behavior of duplex stainless steels, $\mathrm{PhD}$, Grenoble Institute of Technology, France, 2015.

[45] S.S.M. Tavares, J.M. Pardal, M.J.G. da Silva, H.F.G. Abreu, M.R. da Silva, Deformation induced martensitic transformation in a 201 modified austenitic stainless steel, Mater. Charact. 60 (2009) 907-911. doi:10.1016/j.matchar.2009.02.001.

[46] J. Voboril, V. Landa, P.E. Merinov, B.I. Beketov, Problems in the determination of ferrite content of austenitic steels, Strojirenstvi. 29 (1979) 413-422.

[47] I.Y. Pyshmintsev, A. De Meyer, B.C. De Cooman, R.A. Savray, V.P. Shveykin, M.

Vermeulen, The influence of the stress state on the plasticity of transformation induced plasticityaided steel, Metall. Mater. Trans. -Phys. Metall. Mater. Sci. 33 (2002) 1659-1667.

doi:10.1007/s11661-002-0175-5. 


\begin{tabular}{|l|c|c|c|c|c|}
\hline Alloy & $\mathrm{C}$ & $\mathrm{Ni}$ & $\mathrm{Cr}$ & $\mathrm{N}$ & $\mathrm{f}_{\alpha}$ \\
\hline A & 0.02 & 3.63 & 23.91 & 0.19 & 57.9 \\
\hline B & 0.02 & 4.06 & 22.85 & 0.15 & 49.4 \\
\hline C & 0.02 & 4.28 & 22.43 & 0.11 & 51.9 \\
\hline D & 0.02 & 4.58 & 22.15 & 0.07 & 53.3 \\
\hline
\end{tabular}

Table 1: Chemical compositions of alloys A, B, C and D given in wt $\%$. Ferrite fraction $\mathrm{f}_{\alpha}$ in the undeformed state is also provided, those values are calculated from the compositions predicted by Thermocalc.

\begin{tabular}{|l|l|l|l|l|c|}
\hline Alloy & Phase & $\mathrm{Ni}$ & $\mathrm{Cr}$ & $\mathrm{N}$ & $\mathrm{Md} 30\left({ }^{\circ} \mathrm{C}\right)$ \\
\hline \multirow{2}{*}{$\mathrm{A}$} & $\alpha$ & 2.8 & 25.3 & 0.02 & $\mathrm{NA}$ \\
\cline { 2 - 6 } & $\gamma$ & 4.4 & 22.9 & 0.39 & -119 \\
\hline \multirow{3}{*}{$\mathrm{B}$} & $\alpha$ & 2.8 & 25.6 & 0.02 & $\mathrm{NA}$ \\
\cline { 2 - 6 } & $\gamma$ & 4.8 & 21.7 & 0.21 & -13 \\
\hline \multirow{2}{*}{$\mathrm{C}$} & $\alpha$ & 3.0 & 25.6 & 0.02 & $\mathrm{NA}$ \\
\cline { 2 - 6 } & $\gamma$ & 5.3 & 21.1 & 0.16 & -3 \\
\hline \multirow{2}{*}{$\mathrm{D}$} & $\alpha$ & 3.1 & 25.1 & 0.02 & $\mathrm{NA}$ \\
\cline { 2 - 6 } & $\gamma$ & 5.6 & 20.5 & 0.12 & 24 \\
\hline
\end{tabular}

Table 2: Chemical compositions of ferrite and austenite in the four alloys of Table 1 in their undeformed state. Measurements were carried out by microprobe analysis and are given in wt $\%$. Md30 temperatures calculated using the Nohara formula are given for the austenite phase as an indication of its stability during straining.

\begin{tabular}{|l|c|c|c|c|c|c|}
\hline Alloy & $\mathrm{C}$ & $\mathrm{Mn}$ & $\mathrm{Ni}$ & $\mathrm{Cr}$ & $\mathrm{Mo}$ & $\mathrm{N}$ \\
\hline Duplex & 0.021 & 1.15 & 4.24 & 22.12 & 0.28 & 0.12 \\
\hline Austenitic & 0.031 & 1.18 & 5.20 & 20.04 & 0.22 & 0.19 \\
\hline Ferritic & 0.005 & 0.90 & 3.13 & 24.69 & 0.34 & 0.028 \\
\hline A+F & 0.019 & 1.05 & 4.23 & 22.22 & 0.28 & 0.11 \\
\hline
\end{tabular}

Table 3: Compositions of the Duplex alloy, of the austenitic alloy, of the ferritic alloy, and of a hypothetical alloy made of $50 \%$ of the ferritic and austenitic alloys, whose composition is calculated using the rule of mixture. 


\begin{tabular}{|l|c|c|c|c|}
\hline Alloy & $\begin{array}{c}\text { Pre-deformation } \\
(\%)\end{array}$ & $\begin{array}{c}\text { Yield stress } \\
(\mathrm{MPa})\end{array}$ & UTS (MPa) & $\begin{array}{c}\text { Fracture strain } \\
(\%)\end{array}$ \\
\hline \multirow{4}{*}{$\mathrm{A}$} & 0 & 530 & 693 & 23 \\
\cline { 2 - 5 } & 10 & 730 & 783 & 19 \\
\cline { 2 - 5 } & 20 & 914 & 929 & 10 \\
\hline \multirow{3}{*}{ B } & 0 & 500 & 721 & 60 \\
\cline { 2 - 5 } & 10 & 600 & 750 & 53 \\
\hline C & 20 & 859 & 917 & 36 \\
\cline { 2 - 5 } & 0 & 500 & 714 & 62 \\
\cline { 2 - 5 } & 10 & 650 & 792 & 49 \\
\hline \multirow{3}{*}{ D } & 20 & 750 & 871 & 30 \\
\cline { 2 - 5 } & 0 & 433 & 733 & 33 \\
\cline { 2 - 5 } & 10 & 600 & 886 & 25 \\
\hline Duplex & 20 & 685 & 937 & 18 \\
\hline
\end{tabular}

Table 4 : Data for $0.2 \%$ offset yield stress, ultimate tensile strength (engineering stress) and fracture strain (engineering strain) for the four alloys A to D in the undeformed and pre-deformed states, and for the Duplex alloy. 

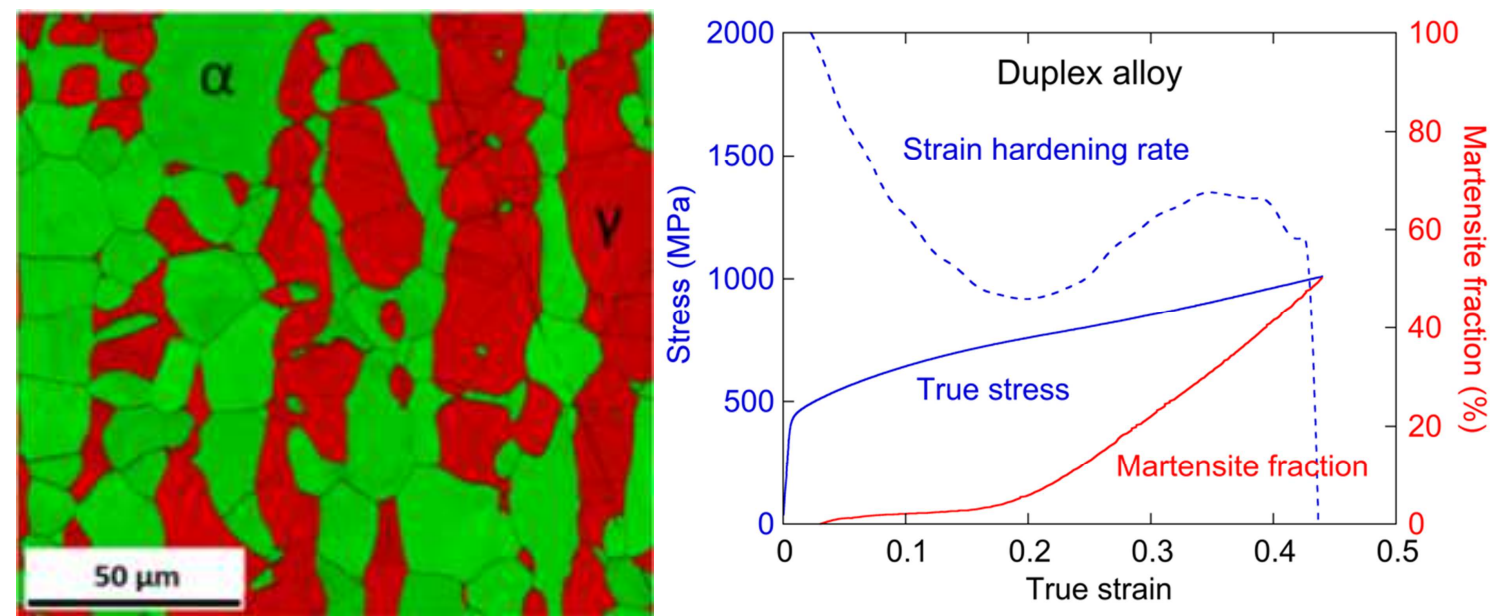

Figure 1: (a) EBSD phase map of the Duplex alloy in the undeformed state with ferrite in green and austenite in red. (b) True stress- true strain curve of the Duplex alloy, calculated strain hardening rate and evolution of the martensite fraction determined by in-situ HEXRD.

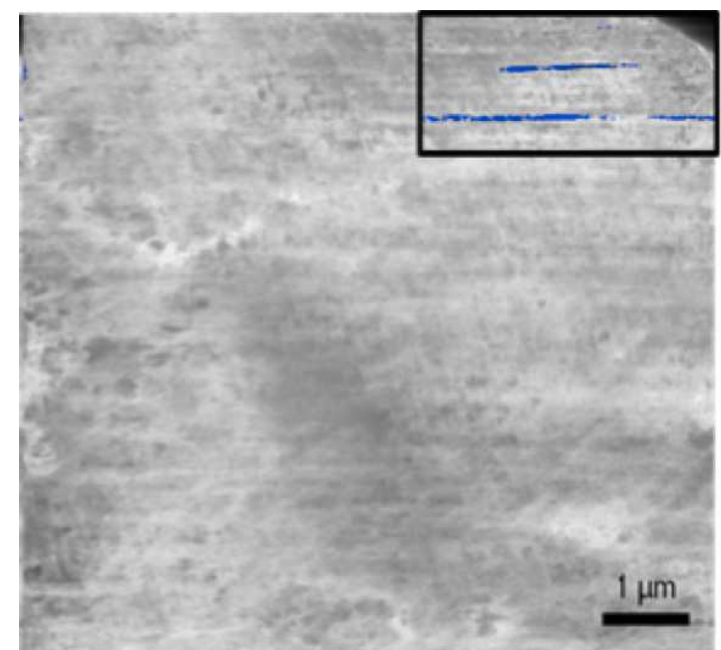

Martensite $\varepsilon$ Austenite $\gamma$

Figure 2: STEM phase map of the Duplex alloy after 10\% true plastic strain. The corresponding pole figures can be found in supplementary material. 


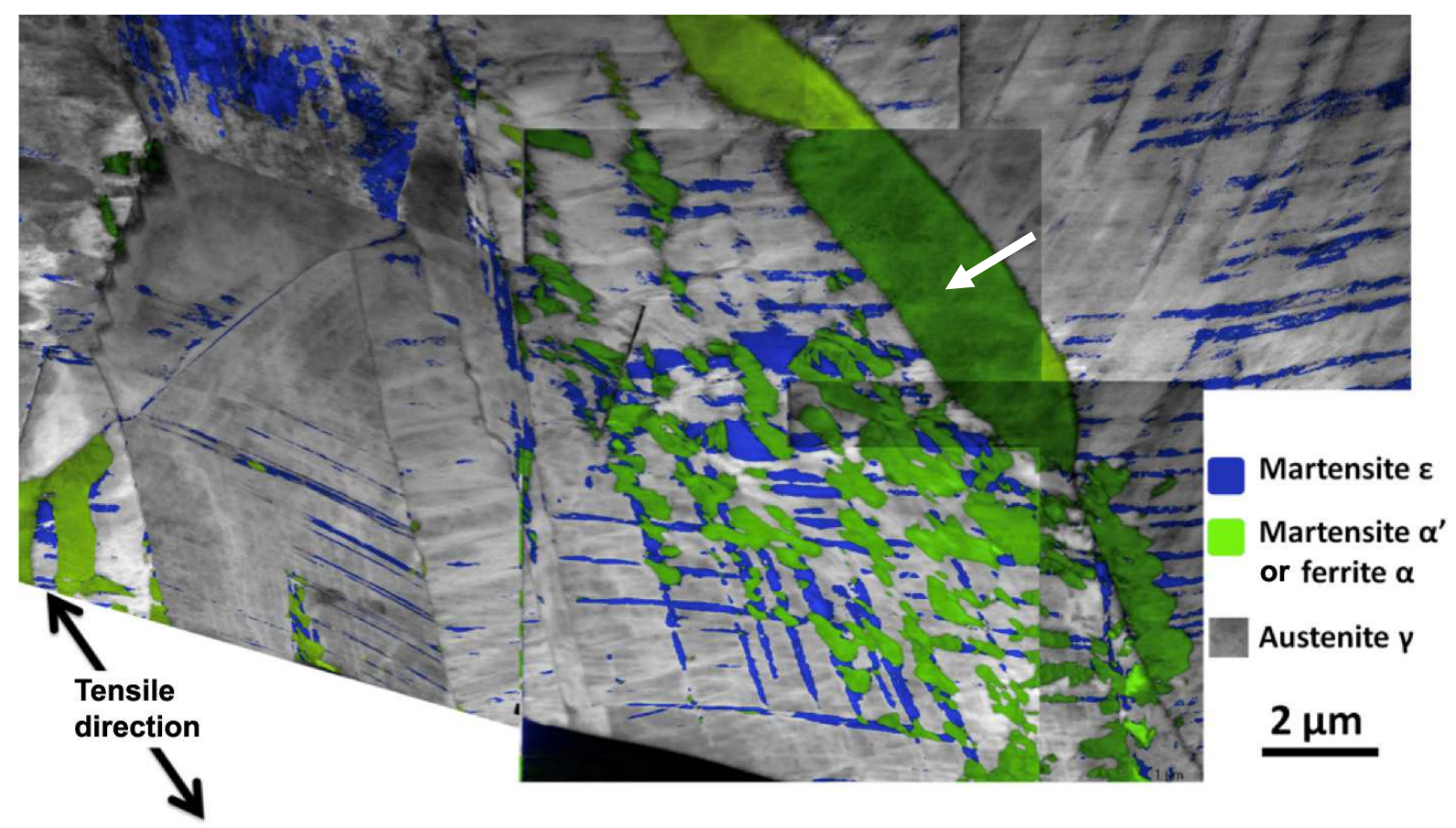

Figure 3: STEM phase map of the Duplex alloy after 20\% true plastic strain. The corresponding orientation map and pole figures can be found in supplementary material. The white arrow delineates an initially ferritic grain.

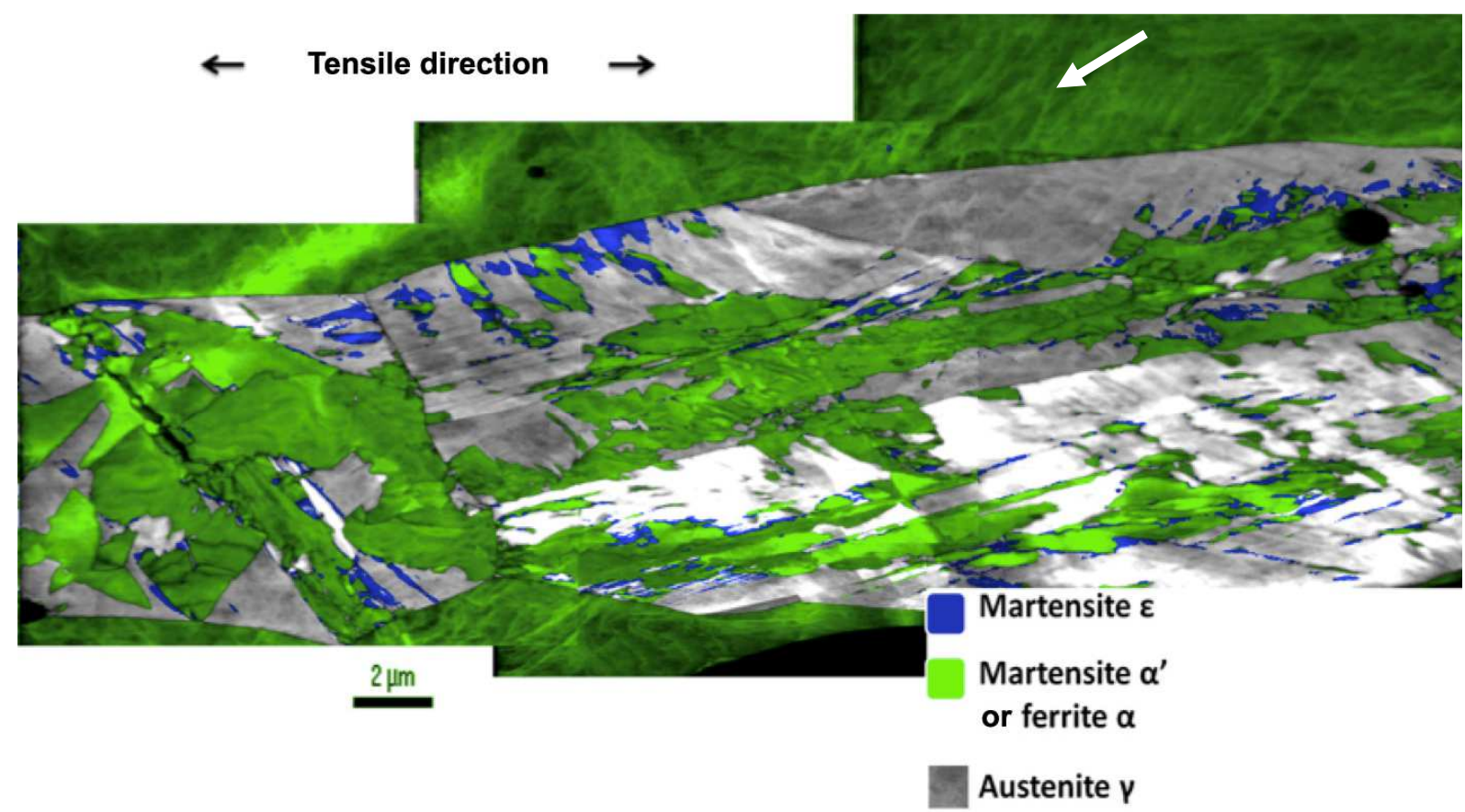

Figure 4: STEM phase map of the Duplex alloy at fracture strain. The corresponding orientation map and pole figures can be found in supplementary material. The white arrow delineates an initially ferritic grain. 


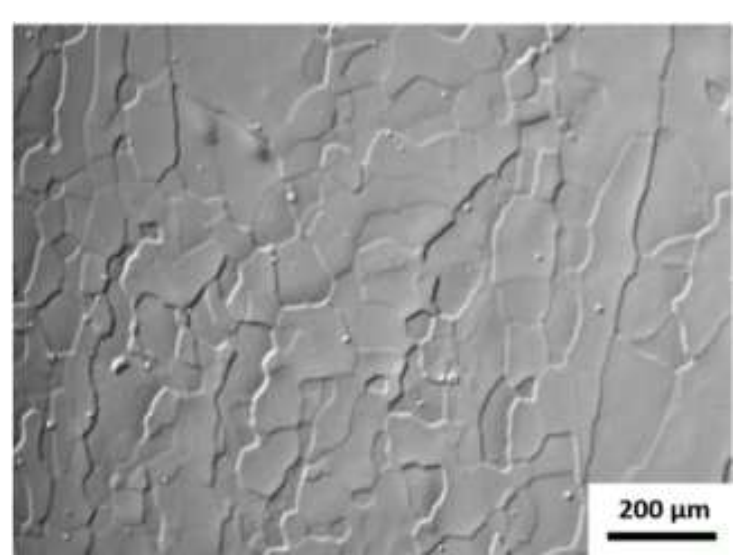

(a)

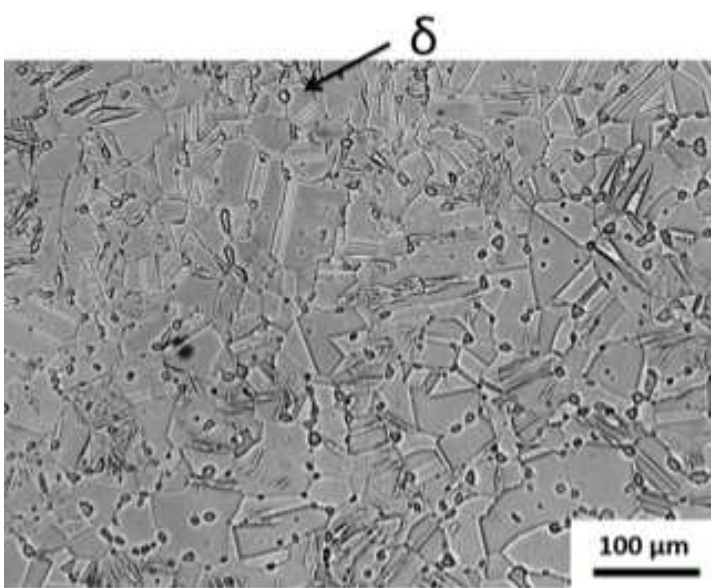

(b)

Figure 5: Optical micrographs showing (a) the grain structure of the ferritic alloy mimicking the ferrite phase of the Duplex alloy and (b) the grain structure of the austenitic alloy mimicking the austenite phase of the Duplex alloy, where one can observe a small residual fraction of undissolved ferrite. 

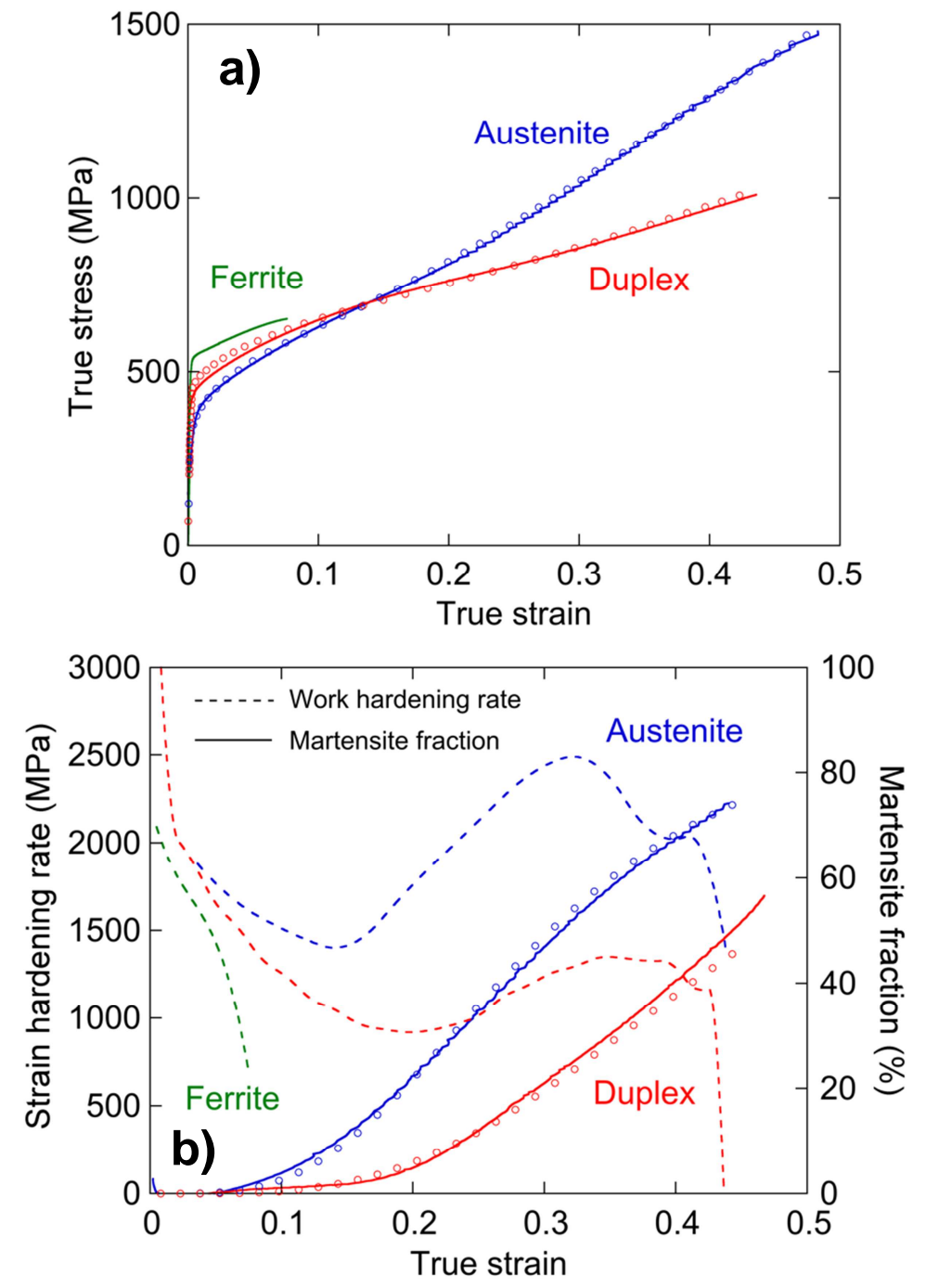

Figure 6: (a) True tress - true strain curves of the Duplex alloy and both the model austenitic and ferritic alloys (lines), along with the modelled curves (symbols) for the last two alloys ; (b) strain hardening rate corresponding to the stress-strain curves of (a) (dashed lines) and corresponding martensite fractions measured by in-situ HEXRD (lines) as well as the modelled fractions (symbols). 
a.

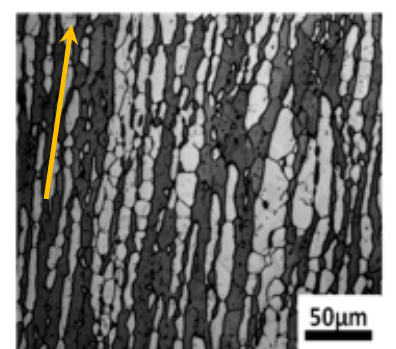

b.

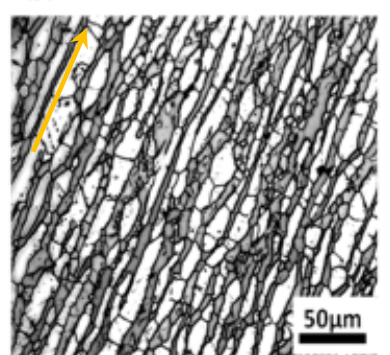

c.

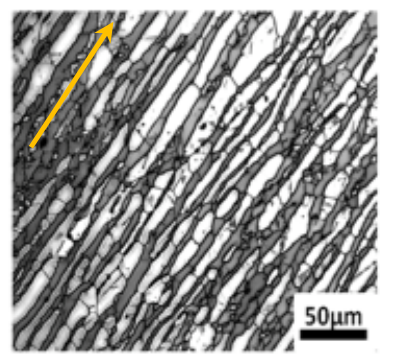

d.

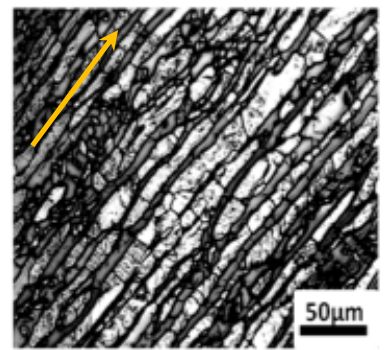

Figure 7: Optical micrographs of the four alloys (a) alloy A ; (b) alloy B ; (c) alloy C ; (d) alloy D, all in the undeformed state. The rolling direction is indicated by an arrow in each image.

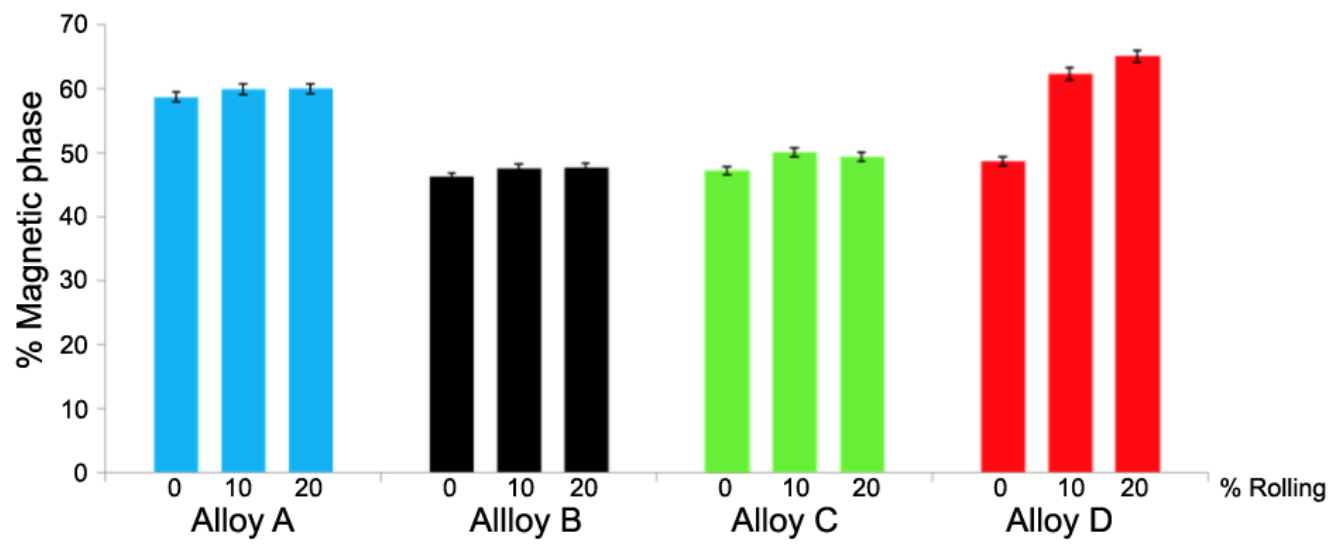

Figure 8: Magnetic measurements of the (ferrite + martensite) phase fraction in the four alloys investigated and its evolution with 10 and $20 \%$ rolling. 


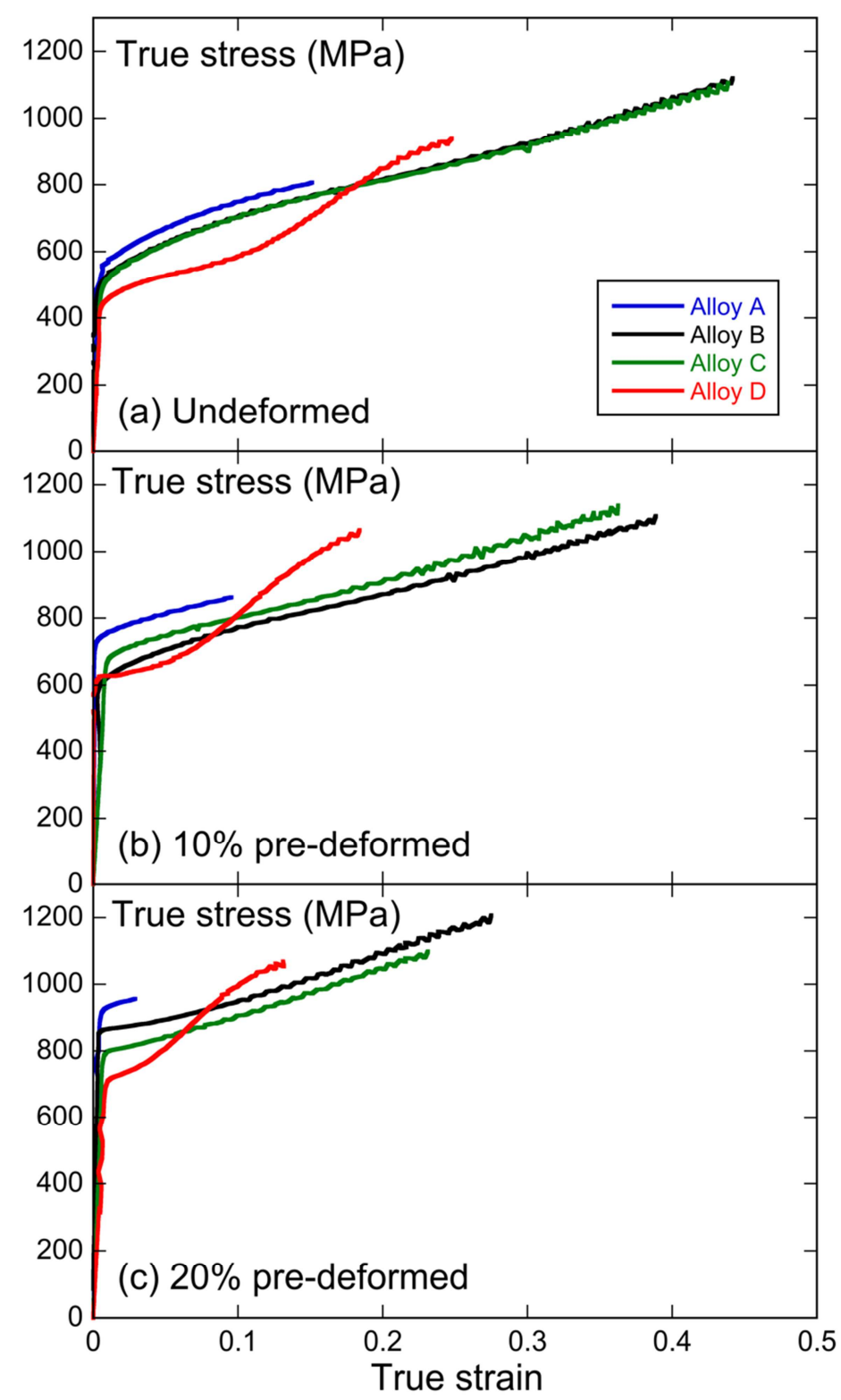

Figure 9: True stress - true strain curves for alloys A, B, C and D with the three different initial conditions: (a) undeformed, (b) pre-deformed $10 \%$ and (c) pre-deformed $20 \%$. 

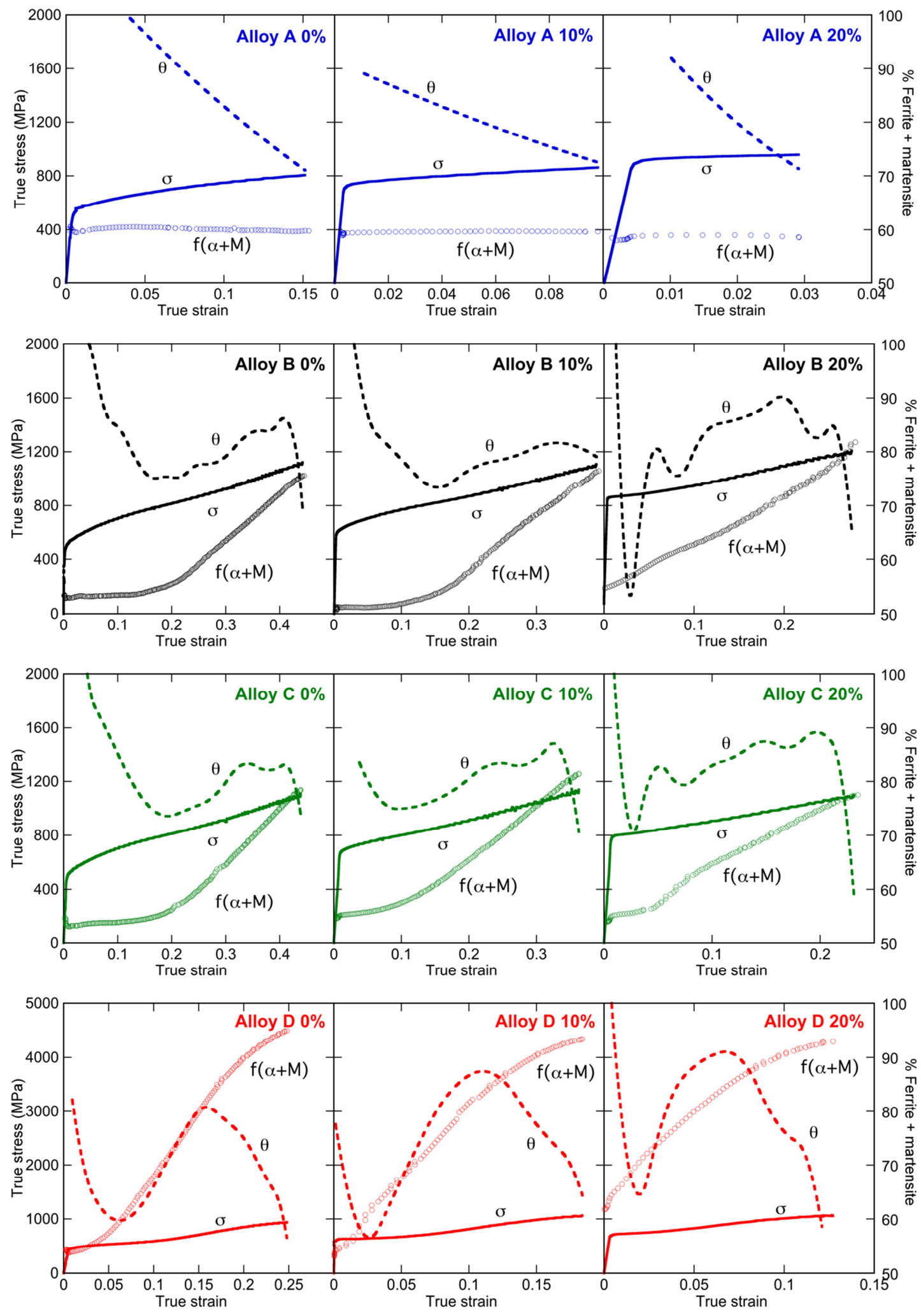

Figure 10: True stress-strain curves for the 4 alloys in the undeformed, $10 \%$ and $20 \%$ deformed states, along with the strain hardening rate $\theta$ and the proportion of ferrite + martensite, measured by in-situ HEXRD. $1^{\text {st }}$ column: Undeformed alloys; $2^{\text {nd }}$ column: $10 \%$ pre-deformed alloys; $3^{\text {rd }}$ column: $20 \%$ pre-deformed alloys. $1^{\text {st }}$ line: alloy A; $2^{\text {nd }}$ line: alloy B; $3^{\text {rd }}$ line: alloy $C ; 4^{\text {th }}$ line: alloy $\mathrm{D}$. 


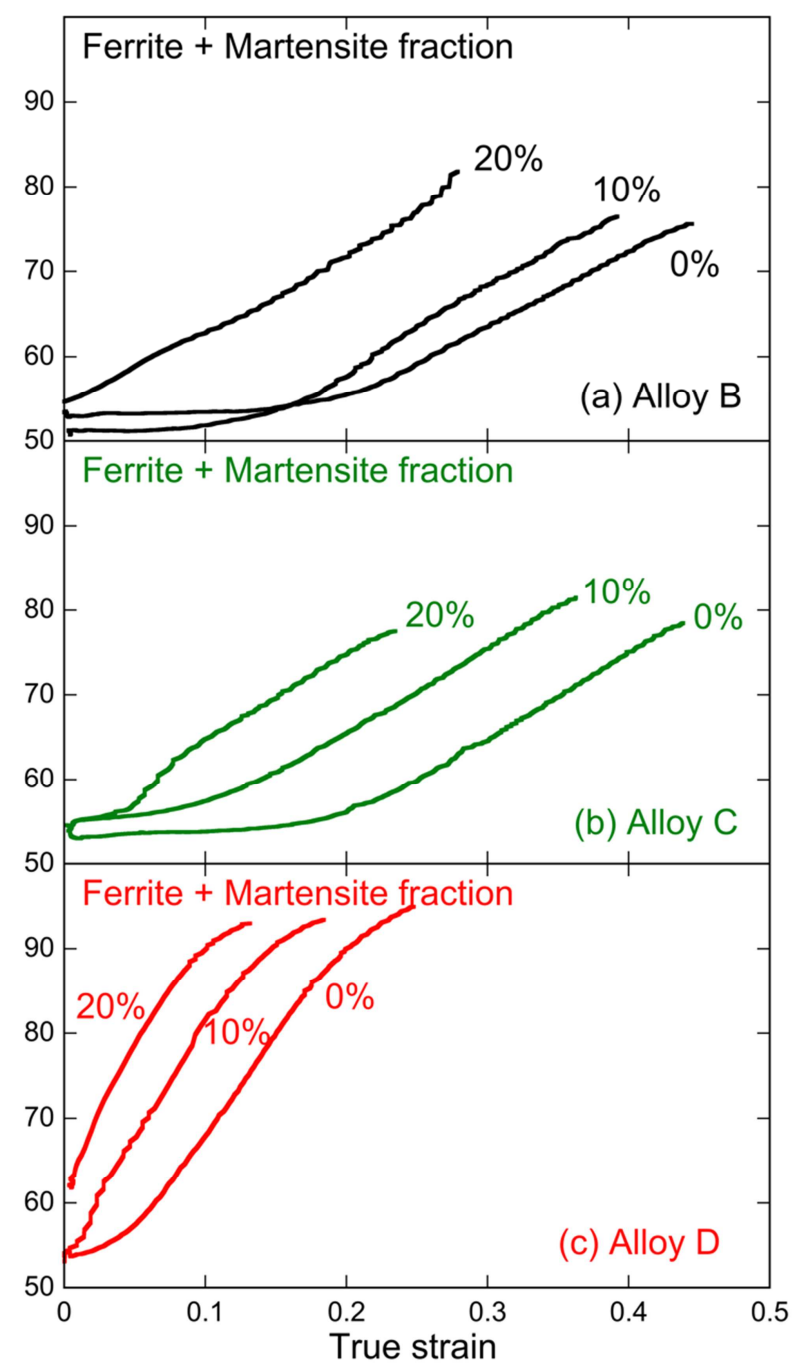

Figure 11: Compared evolutions of the fraction of (ferrite + martensite) during straining in the three alloys showing strain-induced martensite (a) alloy B, (b) alloy C and (c) alloy D, for the undeformed, $10 \%$ pre-deformed and $20 \%$ pre-deformed initial states. 

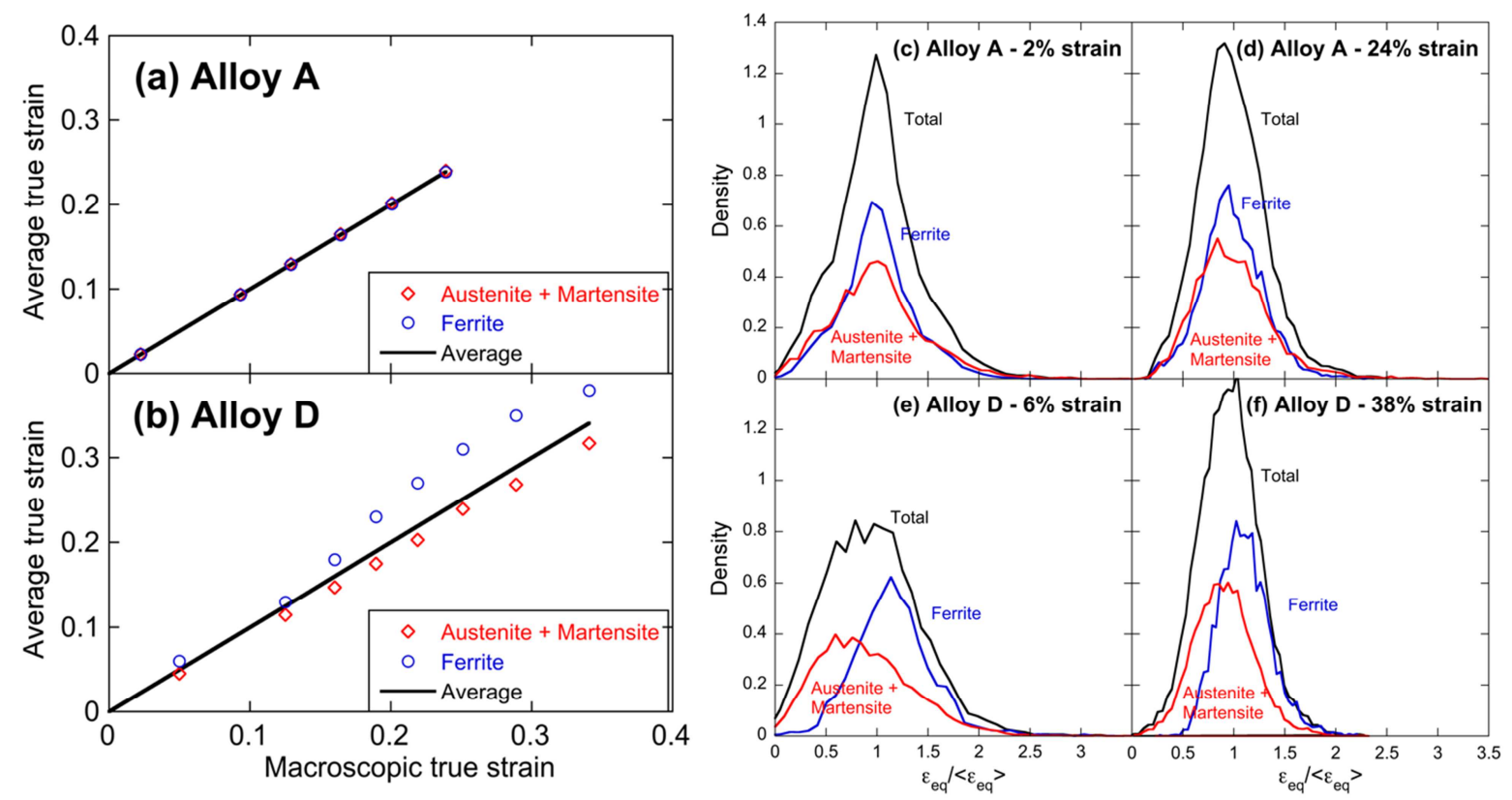

Figure 12: Determination of the strain partitioning: (a) and (b) average distribution of strain in the ferrite phase and within the (austenite + martensite) phases obtained from micro-DIC measurements during in-situ tensile tests for alloys A and D; (c) and (d) distribution of deformations measured on the strain maps for alloy A after $2 \%$ and $24 \%$ strain; (e) and (f) distribution of deformations measured on the strain maps for alloy D after $6 \%$ and $38 \%$ strain.
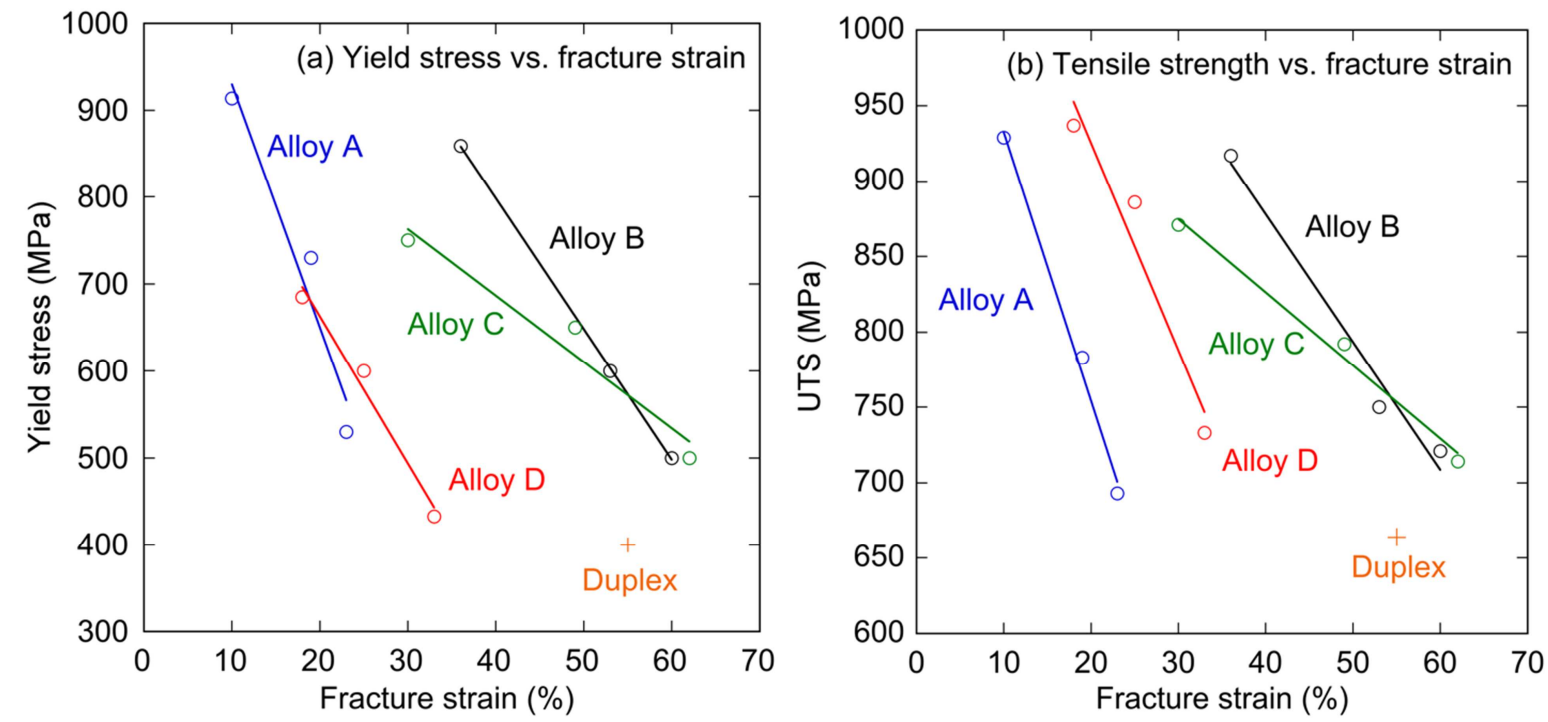

Figure 13 : graphs of (a) Yield stress and (b) UTS as a function of fracture strain, for the four model alloys A to D and the three levels of pre-deformation, and for the Duplex alloy in the undeformed state. 


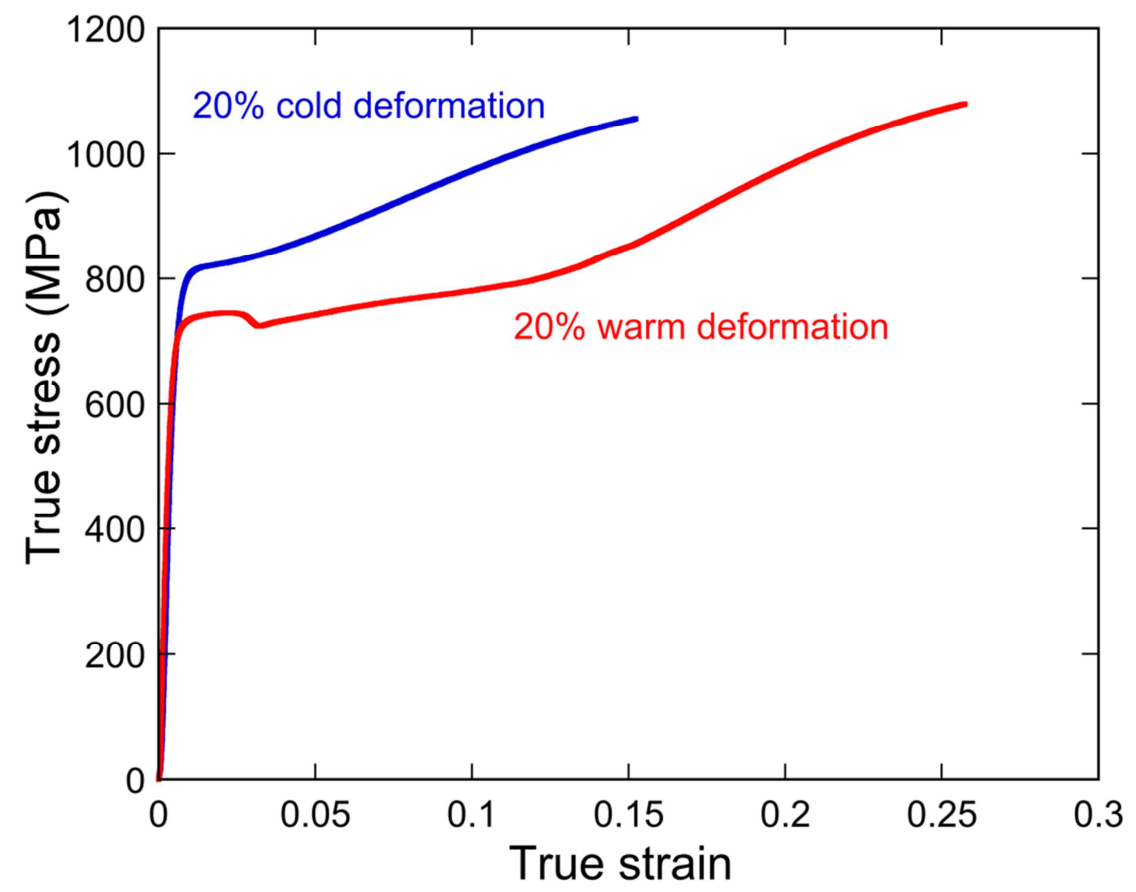

Figure 14: True stress - true strain curves of alloy E, pre-deformed $20 \%$ by cold or warm rolling. 